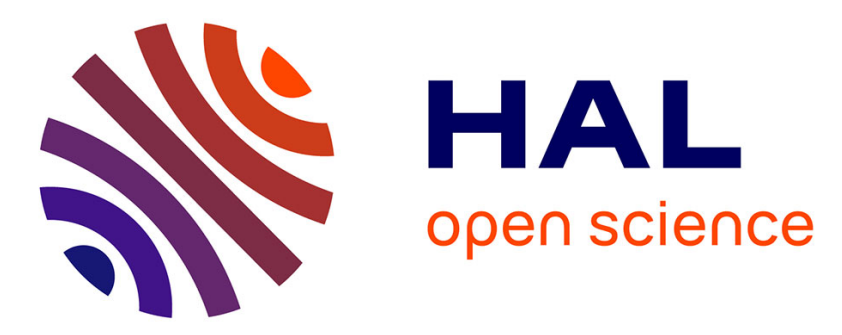

\title{
Correlation between artificial and natural weathering of hemp fibers reinforced polypropylene biocomposites
}

\author{
Célia Badji, J. Beigbeder, Hélène Garay, Anne Bergeret, Jean-Charles
}

Benezet, Valérie Desauziers

\section{- To cite this version:}

Célia Badji, J. Beigbeder, Hélène Garay, Anne Bergeret, Jean-Charles Benezet, et al.. Correlation between artificial and natural weathering of hemp fibers reinforced polypropylene biocomposites. Polymer Degradation and Stability, 2018, 148, pp.117-131. 10.1016/j.polymdegradstab.2018.01.002 hal02479345

\section{HAL Id: hal-02479345 \\ https://hal.science/hal-02479345}

Submitted on 1 Jun 2021

HAL is a multi-disciplinary open access archive for the deposit and dissemination of scientific research documents, whether they are published or not. The documents may come from teaching and research institutions in France or abroad, or from public or private research centers.
L'archive ouverte pluridisciplinaire HAL, est destinée au dépôt et à la diffusion de documents scientifiques de niveau recherche, publiés ou non, émanant des établissements d'enseignement et de recherche français ou étrangers, des laboratoires publics ou privés. 


\title{
Correlation between artificial and natural weathering of hemp fibers reinforced polypropylene biocomposites
}

\author{
Célia Badji, Joana Beigbeder, Hélène Garay, Anne Bergeret*, Jean-Charles Bénézet, \\ Valérie Desauziers
}

C2MA, IMT Mines Ales, Université de Montpellier, 6 avenue de Clavières, 30319 Cedex, France

\begin{abstract}
A B S T R A C T
The degradation behaviors of hemp fibers reinforced PP biocomposites under outdoor and artificial weathering were compared to establish a correlation. For this purpose, several measurements were performed throughout the expositions. Mechanical performance was tested by three-point bending test. Microstructure and chemical composition changes were also assessed. Otherwise, visual aspect and topography were determined. The artificial weathering effectively accelerated the degradation mechanisms. Oxidation pathways and surface aspect alteration of both polymer and biocomposites occurred faster. However, whereas biocomposites were mainly subjected to outdoor conditions due to high sensitivity of hemp fibers, neat PP was globally mostly affected by laboratory chamber conditions. Its oxidation rate largely outstripped reinforced materials ones. Principal Component Analysis was used for verifying the differences of variables correlations profiles between artificial and exterior ageing dataset in order to compare the degradation mechanisms. Through the statistical analysis, some attempts were made to find equivalence between artificial and outdoor weathering times thanks to properties degradation rate similarities.
\end{abstract}

Keywords:

Accelerated ageing

Natural ageing

Statistical method

Hemp fibers

Temporal equivalence

\section{Introduction}

Environmental and production aspect benefits of natural fibers encourage research and industries to develop bio-based materials. Among them, hemp fibers have long been valued for their high strength, and were besides extensively employed in the fabrication of ropes, sails and textiles [1]. Nowadays they are also used as a substitute for glass, carbon or metallic fibers for the reinforcement of thermoplastic matrix. Automotive, building and furniture industries constitute the main application of biocomposites.

Solar radiation, air, oxygen, rain, temperature and biotic factors constitute the main weather features of materials degradation. Some works reported results regarding biocomposites durability. Few trials performing natural weathering of natural fibers and flours reinforced biocomposites are reported in literature [2-4]. Synergic effect combining temperature, humidity and, ultraviolet (UV) radiation causes materials degradation. Even if exposition to real conditions is reliable to interpret the performance loss, it is difficult to understand the contribution of each factor to properties variations. Moreover, outdoor durability test is often laborious and includes irregular changes and slow degradation rate inducing long-term exposures needed to observe noticeable changes. Therefore, artificial weathering carried out in laboratory chambers can substitute them in order to accelerate the degradation phenomenon and predict outdoor weathering [5-7]. They intended to simulate exposure conditions that would potentially be experienced by materials employed in real world applications.

Most of estimations of correlations between artificial and exterior exposition assumed an intimate link of decomposition rate with only UV light since it is widely accepted that photo-chemical reactions are mainly responsible for properties variations of polymers. So UV lamps are supposed to closely simulate spectral power distribution of sunlight [8]. The reciprocity law is classically used to correlate two ageing [9-11]. This law implies that for a same cumulative UV energy under two types of ageing, the degradation degrees are similar even if light intensities differ. Laboratory ageing of polypropylene (PP) was compared to whole year outdoor weathering occurring in Shanghai reasoning only through UV radiation [12]. Intrinsic viscosity and tensile strength values obtained under outdoor exposure were compared to those measured under several lamps UV intensities. It was noticed that, at the same cumulative UV irradiation, the results of test carried out with lamps whose intensities are 82 and $163 \mathrm{~W} \mathrm{~m}^{-2}$ were more compatible with the outdoor weathering test, while test achieved under $325 \mathrm{~W} \mathrm{~m}^{-2}$ lamp induced higher loss of tensile strength. Moreover, it was demonstrated by infrared spectroscopy that a different oxidative

\footnotetext{
* Corresponding author.

E-mail address: Anne.Bergeret@mines-ales.fr (A. Bergeret).
} 
mechanism occurred under $325 \mathrm{~W} \mathrm{~m}^{-2}$ lamp. Thus, the reciprocity law is not verified in this case. Similarly, in another study, the increment of carbonyl absorbance (measured through infrared experiments) of PP against cumulative exposure energy highlighted outdoor exposure as more impactful than accelerated one for a same amount of UV exposure [13]. Yang et al. attempted to correlate outdoor and artificial weathering (UV radiation followed by spray) of polyvinyl chloride (PVC) in terms of cumulative UV radiation energy Q [14]. When samples were subjected to a same $\mathrm{Q}$ value, desaturation and ultimate strength decrease were faster under accelerated ageing than under outdoor one. Therefore, as for previous works, both weathering conditions did not correlate according to the classic reciprocity law. However, results obtained from accelerated and natural weathering fitted by application of a power law generalization of the reciprocity law. Indeed, the power index added to the reciprocity formula and related to materials made consistent the aging levels of samples obtained at different radiation intensities when $\mathrm{E}$ is constant. Nevertheless, even if samples behaviour is highly UV light dependent, it was shown that different weathering performances can occur even if the cumulative energy of UV irradiation is identical [15]. Indeed, depending on light intensity, different compounds having evolved from aged PP were detected. It was noted that different hydroperoxides decomposition pathways could occur generating either carboxylic acids and ketones or esters by varying UV intensity. Also, the lack of agreement between spectral radiation and solar spectrum on one side and the weather variability on the other side may jeopardize a good simulation. Moreover, other exterior factors such as humidity can catalyse photo-degradation [16-18].

Fabiyi et al. conducted simultaneous natural and accelerated weathering of wood plastic composites (WPC). They compared PP matrix degradation of WPC after outdoor and xenon-arc ageing by considering all exterior factors [19]. Similarly, other comparisons were carried out without any calculation of degradation acceleration factor which corresponds to the ratio between time of natural weathering and time of accelerated weathering needed to obtain a same degradation degree $[20,21]$. However, quantitative correlation between artificial and exterior ageing was also performed to find a temporal equivalence by comparing the alteration degree of the analysed materials. Howard and Gilroy studied low-density polyethylene (LDPE) degradation after very long-term natural and Weather-Ometer ageing [22]. On the basis of experimental data, they established an expression verifying the relationship between the two kinds of exposure. This equation indicated that during the early stage of exposure, changes were faster in the Weather-Ometer chamber than outdoor. Nevertheless, when exposition continued further, the efficacy of the accelerated device falls off at an ever increasing rate. Otherwise, the decisive element for use of wood in the harsh outside environment is its durability. Because of slowness of the natural weathering process of wood, the compressive strength values of wood samples recorded all along the artificial weathering were compared to the value obtained after one-year and two-year exterior weathering in Polish temperate climate [23]. The accelerated ageing included soaking $(16 \mathrm{~h})$, high-temperature step at $70^{\circ} \mathrm{C}(8 \mathrm{~h})$, and irradiation at $30^{\circ} \mathrm{C}(6 \mathrm{~h})$. Equivalence was deduced from comparison between these artificial conditions and an exterior weathering by recording intersection of the two sets of data corresponding to a same rate of degradation. It revealed that the number of artificial cycles representing one-year ageing differed according the wood specie. It was found that short cyclical changes highly put samples under stress. Indeed, cyclic exposures tend to be more severe than steady-state exposures [24]. Otherwise, no particular factor was considered as major influential parameter. They suggested that interaction of many exterior factors induce their degradation. In addition, one single acceleration factor does not exist. Indeed, geographical and climatic conditions, materials composition, strongly contribute to the acceleration.

But correlations between natural and artificial ageing were also deduced from different kinds of properties. For instance, Lv et al. determined microstructure, surface morphology and mechanical properties of isotactic polypropylene under several outdoor weathering stations situated in China. They were compared to properties measured under artificial weathering [25]. A modified Arrhenius equation extended to three parameters that are temperature, UV radiation and oxygen pressure, was proposed to correlate properties of outdoor weathered PP with those measured under accelerated ageing. It was demonstrated that a single acceleration factor based on the improved Arrhenius equation and meteorological data could satisfactorily predict outdoor durability. Tidjani et al. estimated an acceleration factor from the carbonyl absorbance whose value was arbitrarily fixed at 0.1 [26]. The acceleration factor (ratio between artificial and natural ageing times needed to obtain absorbance of 0.1) equalled 29. Most of the time, this ratio was often punctually calculated at just one precise time of weathering and fewer verified the ratio over continuous periods.

Artificial weathering should obviously duplicate changes resulting from exterior exposure. However, artificial ageing does not sometimes exactly correlate with natural exposure $[27,28]$. Indeed, Martin et al. conducted artificial and outdoor weathering on polyvinyl chloride (PVC) [29]. Short-period exposure in chamber reproduced same color variations as outdoor whereas longer duration caused darkening that was not observed under natural ageing. Nevertheless, Yang et al. showed that when exposition continues further, the surface color of PVC could gradually change from chalky $(1000 \mathrm{~h})$ to dark $(2000 \mathrm{~h})$ [14]. Thus, this darkening can also result from too long artificial exposition.

As the acceleration factor determination only implies property one by one in literature, the main target of this work is to correlate outdoor and accelerated weathering of PP and hemp fibers reinforced PP biocomposites through several properties in the same time. The investigation focuses on physical, chemical and mechanical properties changes all along the exposure. Then, in view of literature reports conclusions, one must verify whether degradation mechanisms are similar or not through Principal Component Analysis (PCA). Finally, relationships between the two types of ageing by finding temporal equivalence will be attempted.

\section{Materials and methods}

\subsection{Materials}

Polypropylene grade H733-07 with a melt flow rate of $7.5 \mathrm{~g} / 10 \mathrm{~min}$ $\left(230^{\circ} \mathrm{C}, 2.16 \mathrm{~kg}\right)$ purchased from Braskem Co. (Brazil) was used as thermoplastic matrix. Hemp fibers were provided by AgroChanvre (France). The dispersity of hemp fibers whose length (L) and diameter (D) were assessed by optical microscopy (Leica WILD M10, Germany) on 1000 fibers and L/D aspect ratio was measured on 60 fibers is presented in Supplementary Data (Figure S1 and S2). After the retting process, their cellulose, hemicelluloses and lignin rates displayed in Table 1 were determined by successive chemical extractions based on TAPPI T264, ASTM D1104 standards [30,31]. Two hemp fibers loading $10 \mathrm{wt} \%$ (PP10) and $30 \mathrm{wt} \%$ (PP30) were chosen. Maleic anhydride grafted polypropylene (MA-g-PP) coupling agent with a $1 \mathrm{wt} \%$ grafting rate (Orevac CA100) and supplied by Arkema (France), was added at $3.1 \mathrm{wt} \%$ of $\mathrm{PP}$ in the biocomposites.

\subsection{Material processing}

Hemp fibers and MA-g-PP have been dried before process for $15 \mathrm{~h}$ at $60{ }^{\circ} \mathrm{C}$ in an oven to remove residual water. Granules of PP and MA-g-PP

Table 1

Hemp fibers chemical composition.

\begin{tabular}{lllllc}
\hline & Cellulose & Hemicelluloses & Lignin & Lipophilic extractives & Ash \\
\hline (wt\%) & 82.1 & 8.5 & 4.5 & 2.7 & 2.1 \\
\hline
\end{tabular}



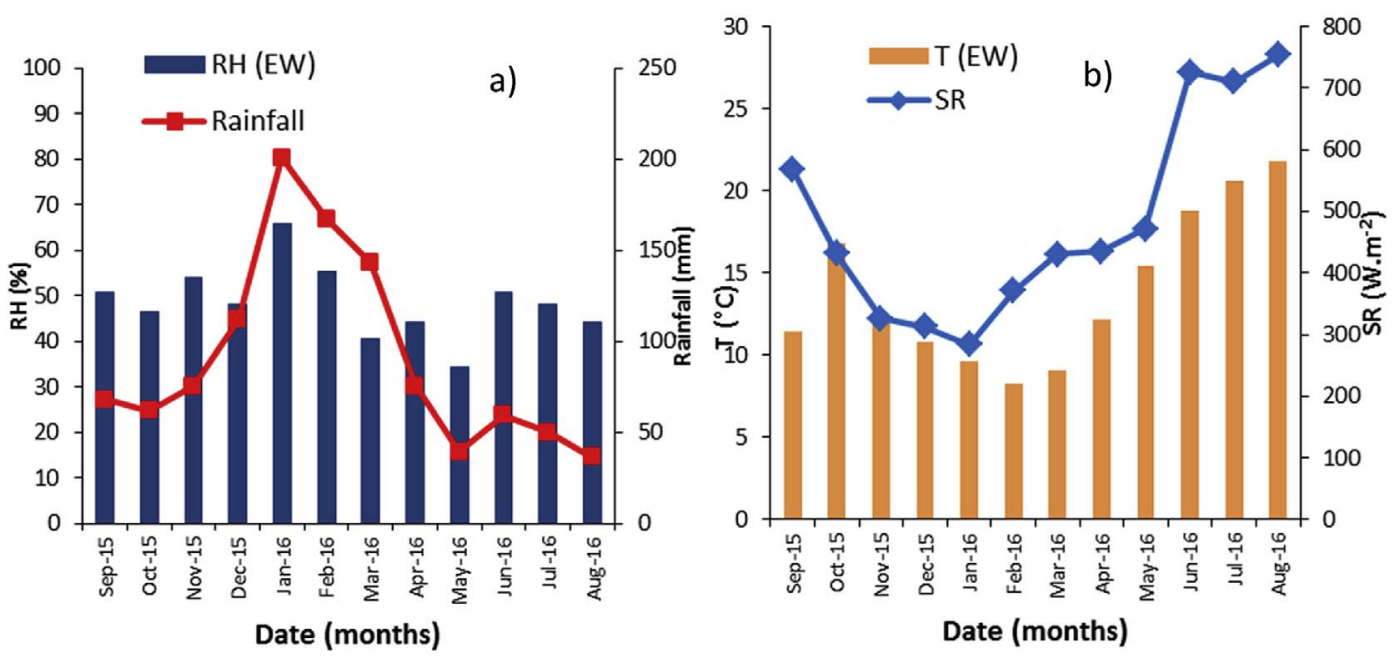

Fig. 1. Mean relative humidity RH (\%) and rainfall (mm) (a) and mean temperature $\mathrm{T}\left({ }^{\circ} \mathrm{C}\right)$ and instantaneous solar radiation maximum SR $\left(\mathrm{W} . \mathrm{m}^{-2}\right)(\mathrm{b})$.

were mixed with hemp fibers in a BC21 Clextral co-rotating twin-screw extruder ( $\mathrm{L} / \mathrm{D}=36$ with the diameter $\mathrm{D}=25 \mathrm{~mm}$ ) (Clextral, France) with the temperature ranging from 190 to $175^{\circ} \mathrm{C}$ from feed to die and a screw speed of $220 \mathrm{rpm}$. Once dried for 3 days at $60^{\circ} \mathrm{C}$, extruded pellets were injection molded in a Krauss Maffei KM50-T180CX (Krauss Maffei, Germany) at $210{ }^{\circ} \mathrm{C}$ with an injection speed of $30 \mathrm{~cm}^{3} \mathrm{~s}^{-1}$ to obtain square specimens of $100 \times 100 \times 2 \mathrm{~mm}$ and ISO 1 dog-bone specimens.

\subsection{Weathering conditions}

\subsubsection{Natural weathering}

Natural weathering was carried out in the South West of France from September 2015 to September 2016. The exterior exposition corresponded to a decking use. The weathering conditions were in adequacy with ISO 877-1:2011 standard [32]. The samples were fixed on galvanized racks at an angle of $45^{\circ}$ with the ground and looked South. Dog-bone and square specimens were sampled after 1, 2, 3, 6, 9 and 12 months for laboratory characterizations. Average seasonal data were recorded from Pau-Uzein meteorological station [33] and are illustrated in Fig. 1.

\subsubsection{Artificial weathering}

Artificial weathering aimed to emulate exterior exposure. QUVSpray apparatus from Q-Lab (Labomat Essor, France) using fluorescent UVA-340 lamps providing $365-295 \mathrm{~nm}$ UV solar spectrum part was used. The conditions followed the ISO 4892-3:2013 standard [34]. Each 12-h weathering cycle consisted of $8 \mathrm{~h}$ of dry UV exposure with an irradiance level of $0.76 \mathrm{~W} \mathrm{~m}^{-2}$ at $\lambda=340 \mathrm{~nm}$ at $50{ }^{\circ} \mathrm{C}$, followed by $3.75 \mathrm{~h}$ of condensation exposure at $50^{\circ} \mathrm{C}$ without irradiation and $0.25 \mathrm{~h}$ spray step. Specimens were collected for analysis after 100, 150, 250, 500,750 and $1000 \mathrm{~h}$ of exposure.

The designation of non-weathered and weathered materials is featured in Table 2.

Table 2

Designation of non-weathered and weathered materials (n: months number, m: hours number).

\begin{tabular}{llll}
\hline & $\begin{array}{l}\text { Unweathered (UW) } \\
\text { materials }\end{array}$ & $\begin{array}{l}\text { Exterior weathered } \\
\text { (EW) materials }\end{array}$ & $\begin{array}{l}\text { Artificial weathered } \\
\text { (AW) materials }\end{array}$ \\
\hline \multirow{2}{*}{ Designation } & PP-UW, PP10-UW, & $\begin{array}{l}\text { PP-EWn, PP10- } \\
\text { EWn, } \\
\text { PP30-UW }\end{array}$ & $\begin{array}{l}\text { PP-AWm, PP10- } \\
\text { AWm, } \\
\text { PP30-AWm }\end{array}$ \\
\hline
\end{tabular}

\subsection{Mechanical characterization}

Flexural properties characterization was conducted using Zwick TH 010 press apparatus with a $2.5 \mathrm{kN}$ load cell. Test was carried out at $23 \pm 2{ }^{\circ} \mathrm{C}$ and $50 \pm 10 \% \mathrm{RH}$ on ISO $1 \mathrm{~A}$ dog-bone samples (ISO 178:2010) [35]. A three point bending system was utilized with crosshead speeds of 2 and $100 \mathrm{~mm} \mathrm{~min}^{-1}$ for the modulus and flexural stress at the conventional deflection measurements respectively. Flexural stress-strain behaviors of samples were analysed in order to determine elastic modulus $\mathrm{E}_{\mathrm{f}}$ calculated between 0.05 and $0.25 \%$ of strain and the stress at the conventional deflection $\sigma_{\mathrm{fc}}$ corresponding to the stress at a strain of 3.5\%. Eight replicates specimens of each material were tested.

\subsection{Visual aspect characterization}

\subsubsection{Spectrocolorimetry}

A Chroma Sensor 3 spectrocolorimeter (Datacolor, United States) was used to measure the surface color according to the CIE $1976 L^{*}, a^{*}$, $b^{*}$ uniform system. The configuration illuminant/observer was set at D65 $/ 10^{\circ}$. An increase of $L^{*}$ (from 0 to 100 ) witnesses a material lightening whereas $\mathrm{a}^{*}$ and $\mathrm{b}$ * are defined as the chromaticity positions on axes from -300 to +300 which are green $\left(-a^{*}\right)$ to red $\left(+a^{*}\right)$ and blue $\left(-b^{*}\right)$ to yellow $\left(+b^{*}\right)$ axes respectively. Color was measured on four areas of three specimens.

\subsubsection{Spectrophotogoniometry}

A GON 360 goniometer (Instrument Systems, Germany) coupled to a MAS 40 spectrometer with a halogen lamp was used to measure the gloss by collecting the radiometric power at different angles of detection. For this purpose, the source angle was fixed at $20^{\circ}$ according to ISO 2813 standard [36] and detector angles varied from $5^{\circ}$ to $-60^{\circ}$. More details are given in a previous paper [20]. The haze gloss $\mathrm{G}_{1}$ was determined from the ratio between the intensity obtained for the angle of detection opposed to the source angle $-20^{\circ}$ and the intensity obtained for the angle of $-22^{\circ}$ both situated in the specular zone (Eq. (1)). The contrast gloss $G_{2}$ was determined from the ratio between the intensity at $-20^{\circ} \mathrm{C}$ and the intensity collected for the angle of $-35^{\circ}$ of a diffusely reflected light (Eq. (2)). The higher the value of $\mathrm{G}_{1}$ and $\mathrm{G}_{2}$ are, the glossier the surface seems. The gloss was calculated for three replicates at four locations on each material.

$G_{1}=\frac{I\left(\Theta=-20^{\circ}\right)}{I\left(\Theta=-22^{\circ}\right)}$

$G_{2}=\frac{I\left(\Theta=-20^{\circ}\right)}{I\left(\Theta=-35^{\circ}\right)}$ 


\subsection{Microstructure characterization}

\subsubsection{Differential scanning calorimetry (DSC)}

The thermal properties were measured using a PYRIS Diamond calorimeter (Perkin Elmer, United States). The samples $(10 \mathrm{mg})$ were heated from 30 to $210{ }^{\circ} \mathrm{C}$ with a heating ramp at $10^{\circ} \mathrm{C} \cdot \mathrm{min}^{-1}$ under nitrogen atmosphere at a $20 \mathrm{~mL} \mathrm{~min}^{-1}$ flow. Two heating steps with an intermediate cooling step were performed. Two replicate samples per material were analysed. The crystallinity degrees $\chi_{\mathrm{c} 1}$ and $\chi_{\mathrm{c} 2}$ were determined from the first and second heating ramp respectively using Equations (3) and (4):

$\chi_{c 1}(\%)=\frac{\Delta H_{m 1}}{W \times \Delta H_{m 100}} \times 100$

$\chi_{c 2}(\%)=\frac{\Delta H_{m 2}}{W \times \Delta H_{m 100}} \times 100$

where $\mathrm{W}$ is the PP mass fraction, $\Delta \mathrm{H}_{\mathrm{m}}\left(\mathrm{J}_{\mathrm{g}}{ }^{-1}\right)$ is the first or second heating ramp melting enthalpy and $\Delta \mathrm{Hm}_{100}$ corresponds to the theoretical melting enthalpy of a fully crystalline PP $\left(\Delta \mathrm{H}_{\mathrm{m} 100}=209 \mathrm{~J} \mathrm{~g}^{-1}\right.$ [37]).

\subsection{Chemical composition characterization}

\subsubsection{Fourier Transform InfraRed spectroscopy (FTIR)}

A IFS66 spectrometer (Bruker, United States) was used in Attenuated Total Reflectance (ATR) mode to follow the functional groups assigned to the samples degradation. The exposed surfaces were analysed and the spectra of materials were recorded between 400 and $4000 \mathrm{~cm}^{-1}$ with a resolution of $1 \mathrm{~cm}^{-1}$. In order to normalize the spectra, the Min-Max normalization method of the spectra with the $2925 \mathrm{~cm}^{-1}$ reference band assigned to the $\mathrm{CH}_{2}$ methylene groups was performed.

\subsection{Surface characterization}

\subsubsection{Confocal rugosimetric measurement}

A MICROMESURE STIL system equipped with a STIL CHR150 optical sensor (STIL, France) was used to evaluate the roughness by altitude measurement of each surface point on the sample without contact with the sample according to the ISO 25178 international standard. The analysis principle is detailed elsewhere [20]. The micrometric range of the optical pen was $285 \mu \mathrm{m}$. The analysed area $X^{*} Y$ was $5 \mathrm{~mm} \times 5 \mathrm{~mm}$ with an analysis step of $10 \mu \mathrm{m}$ in $\mathrm{X}$ and $\mathrm{Y}$ directions. The roughness parameter Sa followed during the weathering corresponds to the arithmetic mean of the absolute of the height values (Eq. (5)).

$\mathrm{Sa}=\frac{1}{N M} \sum_{x=0}^{N-1} \sum_{y=0}^{M-1}|z(x, y)|$

with $\mathrm{M}$ the number of points along the $\mathrm{X}$ axis, $\mathrm{N}$ the number of points along the $\mathrm{Y}$ axis, and zx,y the altitude in $\mu \mathrm{m}$. Mean values and standard deviations were obtained from the analysis of four areas of three samples.

\subsection{Principal Component Analysis (PCA)}

Principal Component Analysis (PCA) gives a simple graphical overview on large set of observations of variables (properties) by data reduction. It also estimates the correlation structure of the variables and relatedness between populations. Statistica 13 (Dell, France) software was employed for the statistical calculation. Statistical analysis was used to compare dataset of exterior and accelerated ageing. This aimed to first verify if the relationships established between properties are similar for the two weathering. Then, the method was used to attempt correlating the two weathering by individuals (samples) analysis. Variables values were centered-reduced to scale them for overcoming
Table 3

Designation of variables.

\begin{tabular}{ll}
\hline Designation & Parameter \\
\hline $\mathrm{E}$ & Modulus of elasticity (MPa) \\
$\mathrm{s}$ & Stress at the conventional deflection (MPa) \\
$\chi_{\mathrm{c} 1}, \chi_{\mathrm{c} 2}$ & Crystallinity rate from 1 st and 2nd heating steps (\%) \\
$\mathrm{A} 1$ & Absorbance $\mathrm{C}=\mathrm{O}$ at $1711 \mathrm{~cm}^{-1}$ (carboxylic acids and ketones) \\
$\mathrm{A} 2$ & Absorbance $\mathrm{C}=\mathrm{O}$ at $1740 \mathrm{~cm}^{-1}$ (esters and aldehydes) \\
$\mathrm{A} 3$ & Absorbance $\mathrm{C}=\mathrm{O}$ at $1780 \mathrm{~cm}^{-1}(\gamma$-lactones) \\
$\mathrm{A} 4$ & Absorbance $\mathrm{C}=\mathrm{C}$ at $1650 \mathrm{~cm}^{-1}$ (vinyls) \\
$\mathrm{Sa}$ & Roughness $(\mu \mathrm{m})$ \\
$\mathrm{G} 1$ & Haze gloss \\
$\mathrm{G} 2$ & Contrast gloss \\
$\mathrm{L}^{*}$ & Lightness (light-dark) \\
$\mathrm{a} *$ & Chromatic coordinate (red-green) \\
$\mathrm{b}^{*}$ & Chromatic coordinate (yellow-blue) \\
\hline
\end{tabular}

domination of variables with the highest variance. Table 3 resumes denominations of variables.

\section{Results and discussion}

\subsection{Mechanical performance}

Flexural properties of PP and biocomposites were determined all along one-year outdoor (EW) and 1000-h artificial (AW) weathering. Their changes are illustrated in Fig. 2. The higher values of biocomposites mechanical properties recorded whatever the time and type of exposure are associated with the reinforcement and stiffening effect of vegetal fibers. However, elastic modulus $\left(\mathrm{E}_{\mathrm{f}}\right)$ and conventional deflection stress $\left(\sigma_{\mathrm{fc}}\right)$ of all materials declined during the two weatherings due to polymer and hemp fibers degradation.

Otherwise, the longest-time accelerated ageing more affected more elastic modulus of PP and PP/hemp fibers composites than outdoor one due to high number of cyclical changes in moisture, temperature and UV radiation in short times [23]. Also, the performance loss rate over ageing increased from PP to PP30 after exterior ageing whereas it decreased after artificial one. Indeed, elastic modulus decreased by $20 \%$ and $8 \%$ for PP30-EW and neat PP-EW respectively after 12 months. On the contrary, it diminished by $30 \%$ and $41 \%$ for PP30-AW and PP-AW respectively after $1000 \mathrm{~h}$. This can be explained by either different degradation mechanisms during EW and AW leading to different performance loss speeds or too-long exposition corresponding to more than 1 year of natural exposure covered by the accelerated ageing. The properties presented later will allow further understanding of these variations and target the possible reasons of differences.

As regards trend of $\sigma_{\mathrm{fc}}$ changes, neat PP stress was more influenced than PP30 whatever the type of weathering after the total duration. Also, in the last six months, $\sigma_{\mathrm{fc}}$ of PP-EW fell by $21 \%$ whereas it remained almost constant before. After a $250-\mathrm{h}$ stable period, it linearly dropped by $36 \%$ for PP-AW. Thus, artificial ageing amplified the strength loss.

\subsection{Microstructure}

The crystallinity degree of polymer was influenced by the weathering (Fig. 3). Indeed, even if the photodegradation is prevalent in the amorphous phase whose molecular chains can further crystallize, the global decrease of crystallinity rate suggests that crystalline phase was mostly affected $[3,38]$. Firstly, $\chi_{\mathrm{c} 1}$ was slightly less impacted by weatherings than $\chi_{\mathrm{c} 2}$. Indeed, the main difference is noted for PP-AW decreasing from $46.1 \pm 0.2 \%$ to $33.3 \pm 1.6 \%$ and from $51.0 \pm 0.3 \%$ to $25.0 \pm 2.8 \%$ for $\chi_{\mathrm{c} 1}$ and $\chi_{\mathrm{c} 2}$ respectively at the end of the AW. Moreover, some differences were noted between AW and EW. Indeed, the high absolute curve slope of $\chi_{\mathrm{c} 2}$ evolution of artificially aged materials indicates a higher kinetic of crystallinity rate decrease under 

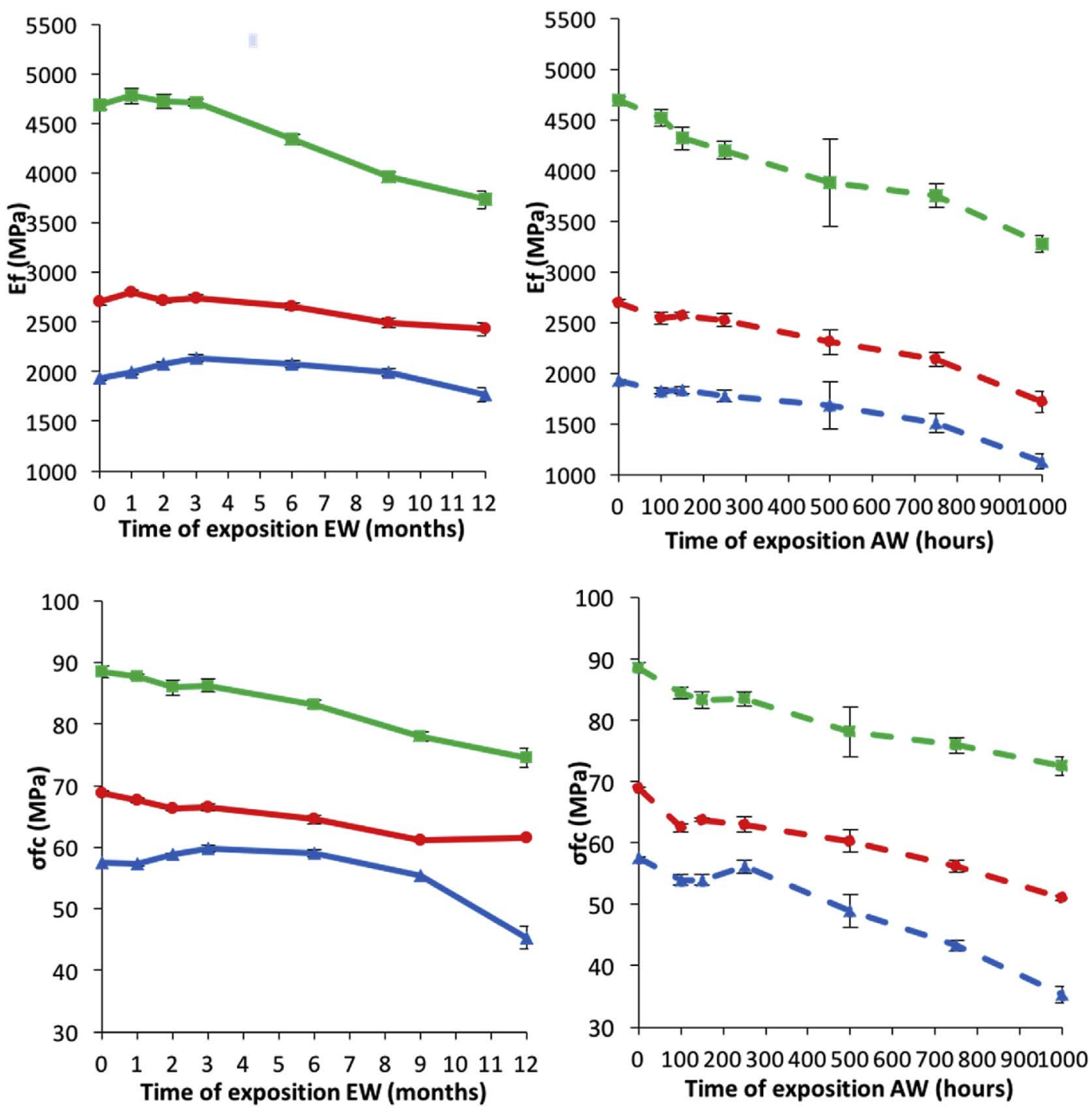

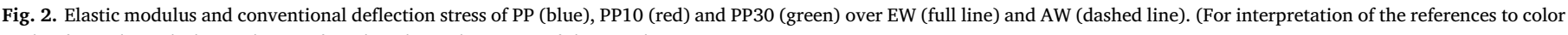
in this figure legend, the reader is referred to the Web version of this article.)

artificial weathering conditions. For instance, $\chi_{\mathrm{c} 2}$ of PP-AW exhibited a drastic decrease of $50 \%$ in $1000 \mathrm{~h}$ whereas PP-EW one lost only $7 \%$ of its crystallinity degree original value after 12 months. Otherwise, unlike for EW, neat PP was more subjected to QUV chamber conditions than PP10 and PP30. These observations match with results obtained from modulus measurements. It is noted that only $\chi_{\mathrm{c} 1}$ corresponds to materials microstructure when mechanically tested.

\subsection{Chemical structure}

It is common to monitor photooxidation products in the 1700 $1800 \mathrm{~cm}^{-1}$ region of FTIR spectra of polymers throughout their ageing. Thus, carbonyls compounds including carboxylic acids in the dimer form and ketones, esters and aldehydes, and lactones peaking at 1711, 1740 and $1780 \mathrm{~cm}^{-1}$ respectively were analysed [15]. Thermoplastic polymers can also undergo chain scission inducing vinyl species formation whose $1650 \mathrm{~cm}^{-1}$ infrared band attests its presence. The analysis is hence focused on absorption bands between 1490 and $1830 \mathrm{~cm}^{-1}$. The infrared spectra of materials that were unweathered, artificially weathered for $1000 \mathrm{~h}$ and exterior weathered for one year are featured in Fig. 4.

Firstly, increase of all carbonyl and vinyl bands with the fiber loading comes from $\mathrm{C}=\mathrm{O}$ and $\mathrm{C}=\mathrm{C}$ bonds naturally present in cellulose, hemicelluloses and lignin. Also, their increase after exposition of all materials corroborates oxidative mechanism and scission of polymer chains. It can be noticed that lactones level of each material was not influenced by the kind of ageing after $1000 \mathrm{~h}$ and one year of accelerated and exterior weathering respectively at the opposite of other carbonyl derived substances whatever the material. Indeed, oxidative degradation rate recorded after $1000 \mathrm{~h}$ of AW corresponding to 41 days is higher than those after 1 year of EW. So artificial ageing was more impactful than exterior ageing for durations that were chosen in this work.

Similarly, C = C bond peak height was higher for PP-AW1000 than for PP-EW12 whereas no difference was observed for biocomposites. PP was, once again, mainly sensitive to laboratory chamber conditions that accelerated polymer chain scissions.

The maximum absorbance evolutions of $\mathrm{C}=\mathrm{O}$ carboxylic acid and ketone bonds $\left(1711 \mathrm{~cm}^{-1}\right), \quad \mathrm{C}=\mathrm{O}$ ester and aldehyde bonds $\left(1740 \mathrm{~cm}^{-1}\right), \mathrm{C}=\mathrm{O} \gamma$-lactone bond $\left(1780 \mathrm{~cm}^{-1}\right)$ and $\mathrm{C}=\mathrm{C}$ vinyl bond $\left(1650 \mathrm{~cm}^{-1}\right)$ with the ageing time and type (EW, AW) are showed on Fig. 5. Oxygenated products aroused from hydroperoxide species formed under UV rays and high temperature of the two types of weathering that can decompose into alkoxy radicals which dissociate into lower molecular weight products $[25,39]$. However, the increase rate of oxygenated products was lower after natural ageing than after 

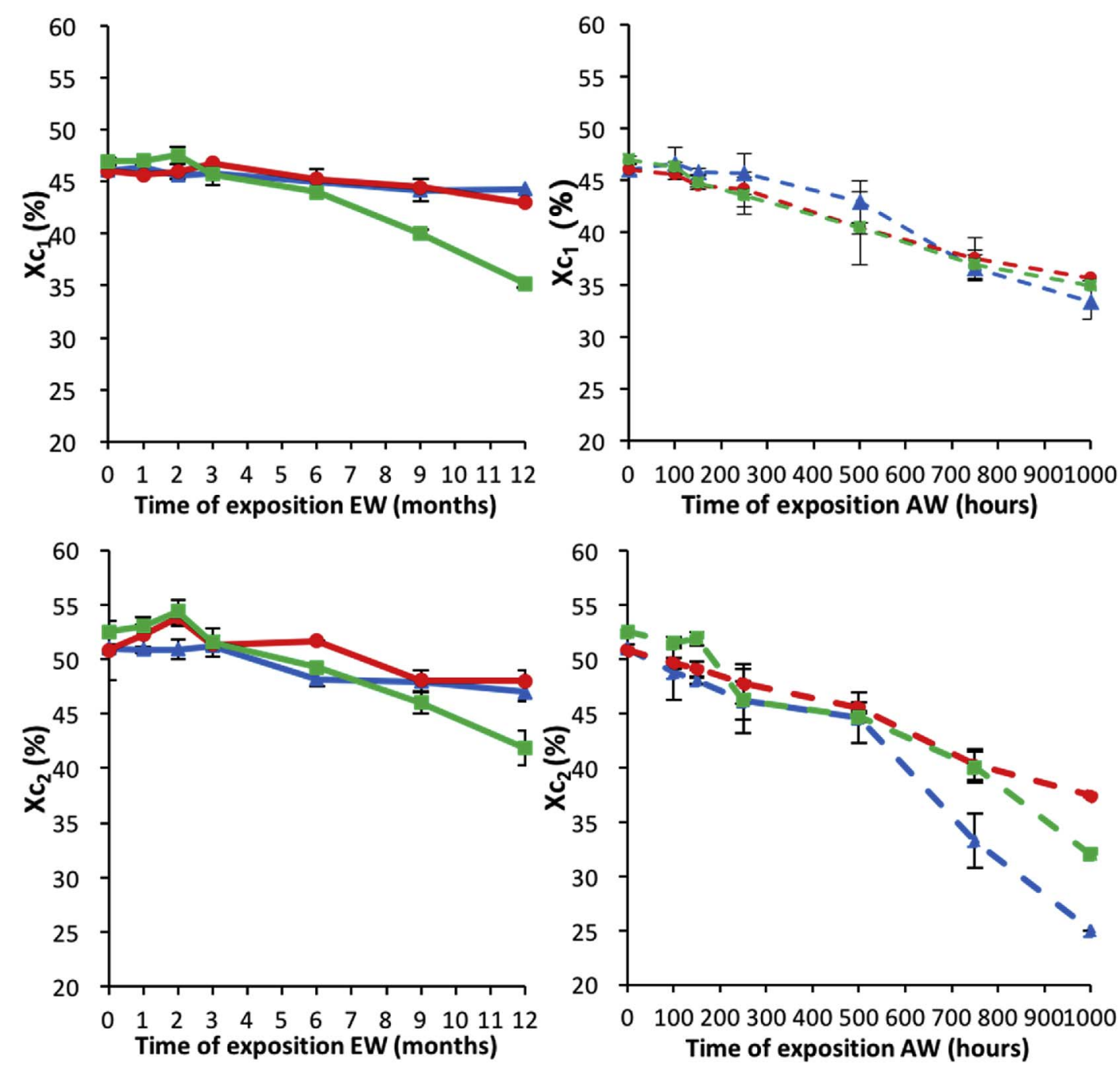

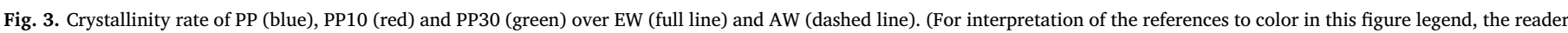
is referred to the Web version of this article.)

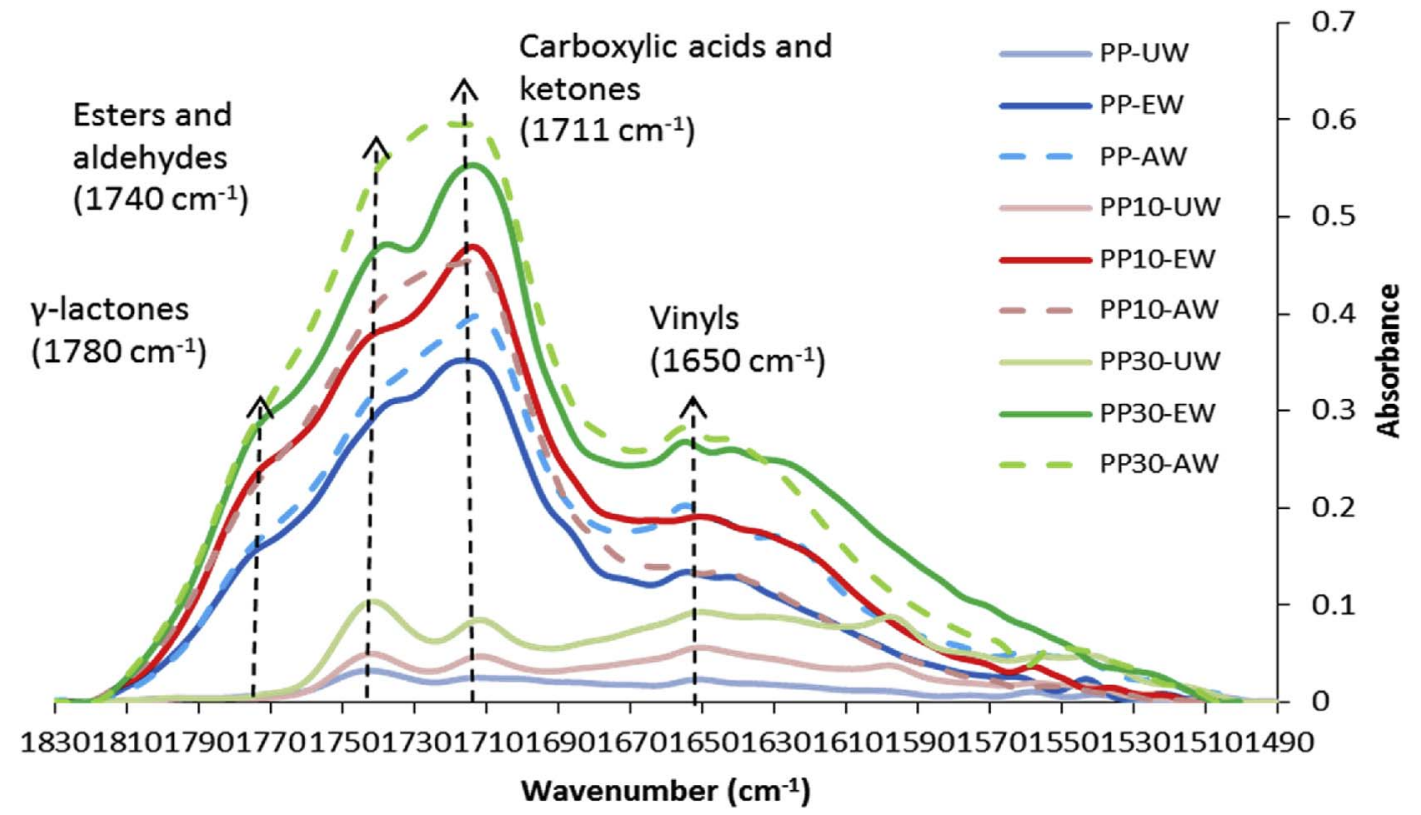

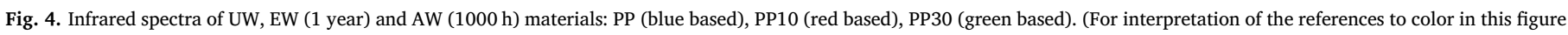
legend, the reader is referred to the Web version of this article.) 

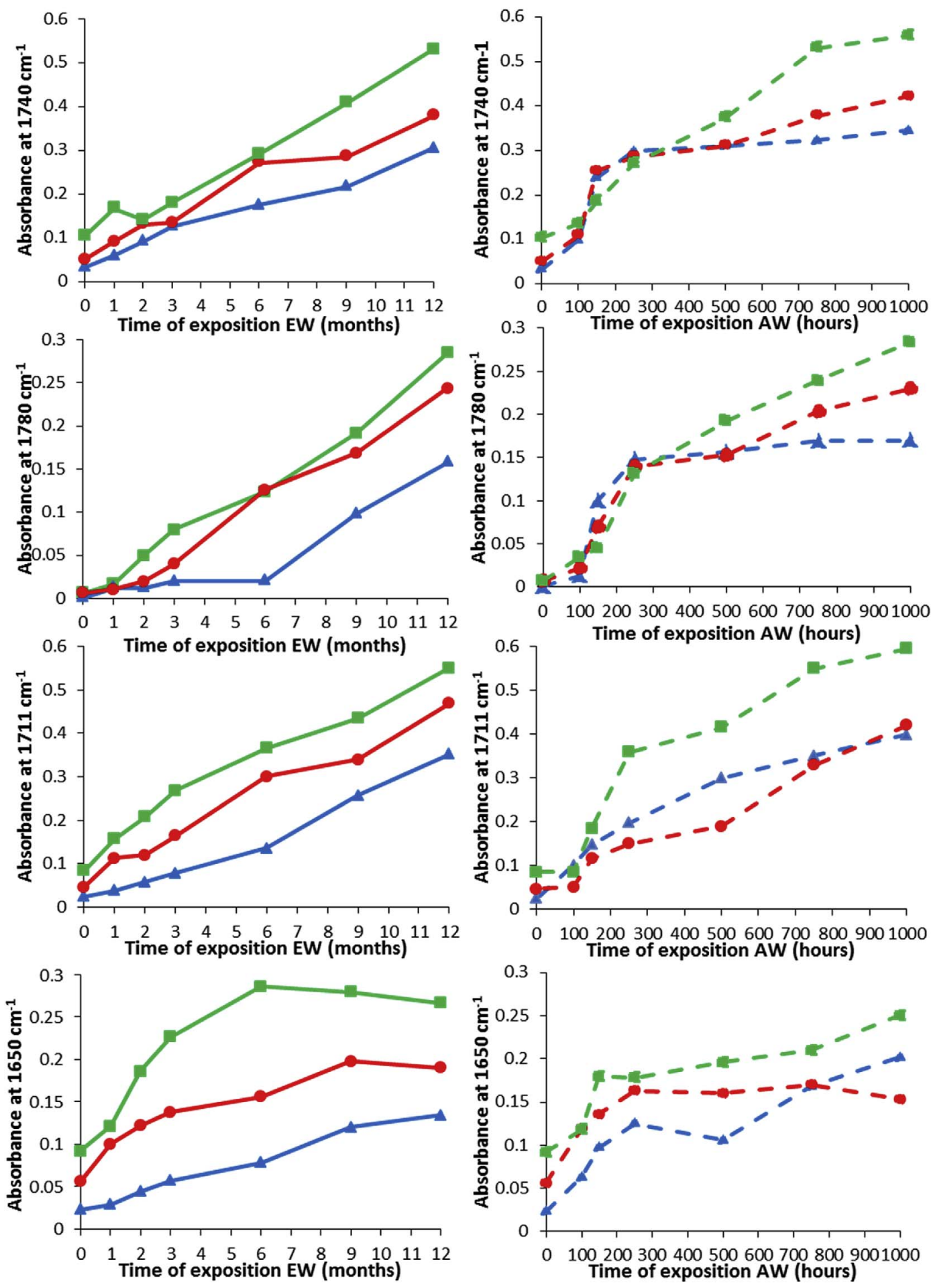

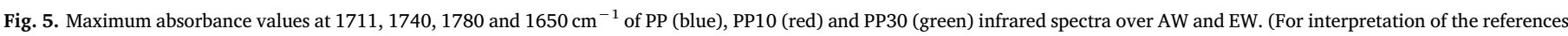
to color in this figure legend, the reader is referred to the Web version of this article.)

artificial ageing whatever the material. Otherwise, this trend was even more valid for neat PP. So, artificially aged PP underwent stronger oxidative degradation.

As regards carbonyl bonds evolution profile, results show that esters and aldehydes $\left(1740 \mathrm{~cm}^{-1}\right)$ on one hand and lactones $\left(1780 \mathrm{~cm}^{-1}\right)$ on another hand evolving from PP degradation reached a constant absorbance value after $250 \mathrm{~h}$ of 0.3 and 0.15 respectively whereas ketones and carboxylic acids $\left(1711 \mathrm{~cm}^{-1}\right)$ were progressively detected for artificial weathering. This suggests that, at this weathering stage, ketones and acids were formed to the detriment of the previous ones. Same evolution was observed for biocomposites with a slightly slower increase of esters, aldehydes and lactones generation after $250 \mathrm{~h}$ rather than a plateau. Therefore, ketones and acids groups could be favored in these conditions of humidity, UV radiation and temperature. Concerning exterior weathering, continuous increase of these oxygenated compounds was recorded. However, the maximum shifted from 1740 to $1711 \mathrm{~cm}^{-1}$ from non-weathered to weathered state whatever the type of weathering. The hydrolysis of ester species leading to carboxylic acids could be responsible to the $1711 \mathrm{~cm}^{-1}$ band level increase. 
$\gamma$-lactones generally originating from intramolecular reactions could evolve from back-bitting mechanism [25]. Otherwise, the evolution of lactones absorbance peak reveals an auto-accelerated shape meaning first induction stage followed by rapid increase and steady state period [40]. A short induction period, of about $100 \mathrm{~h}$, is observed for PP-AW whereas this stage lasted 6 months for PP-EW.

As regards vinyl bonds evolution profiles, biocomposites level stabilized after almost 6 months and $250 \mathrm{~h}$ of natural and accelerated weathering respectively. Indeed, enolic groups can further rearrange into carbonyl species [41]. Also, even if they exhibit the same evolution profile, vinyl groups level less increased for AW biocomposites than for EW ones. It can be due to continuous high temperature in chamber $\left(50{ }^{\circ} \mathrm{C}\right)$ inducing the higher decrease of vinyls to the profit of carbonyls [25]. However, a different tendency is observed for neat PP since, as for ketones evolution, it progressively increased. Moreover, the amount of $\mathrm{C}=\mathrm{C}$ species after one year corresponds to $250 \mathrm{~h}$ of accelerated ageing. Thus, this mechanism seems to correlate with an acceleration of degradation rate of PP under conditions of artificial exposure that were applied in this study.

\subsection{Visual appearance}

\subsubsection{Color}

Fig. 6 depicts lightness evolution versus exposure time. PP was not significantly influenced by the ageing. Nevertheless, results showed that lightness increased for biocomposites because of fibers photodegradation and structural changes. As reported in literature, oxidoreduction process of lignin leading to formation of hydroquinones due to chromophore structures formation in lignin may induce whitening [4]. The bleaching kinetics of PP10-AW and PP30-AW were more important than those of PP10-EW and PP30-EW respectively. Otherwise, PP30 bleaching saturated at almost 75 after 3 months of EW and $250 \mathrm{~h}$ of AW. This can be explained by the increasing rate of holocellulose at the surface being uncovered after biocomposites exposition. Otherwise, they degraded in a similar manner. Thus, the type of weathering did not modify the evolution profile.

Fig. 7 shows $\mathrm{a}^{*}$ and $\mathrm{b}^{*}$ colorimetric coordinates in a two-dimension space.

Results show that PP colorimetric coordinates was not highly influenced by the two types of ageing.

As concerns $\mathrm{a}^{*}$ coordinate values, results showed that non-

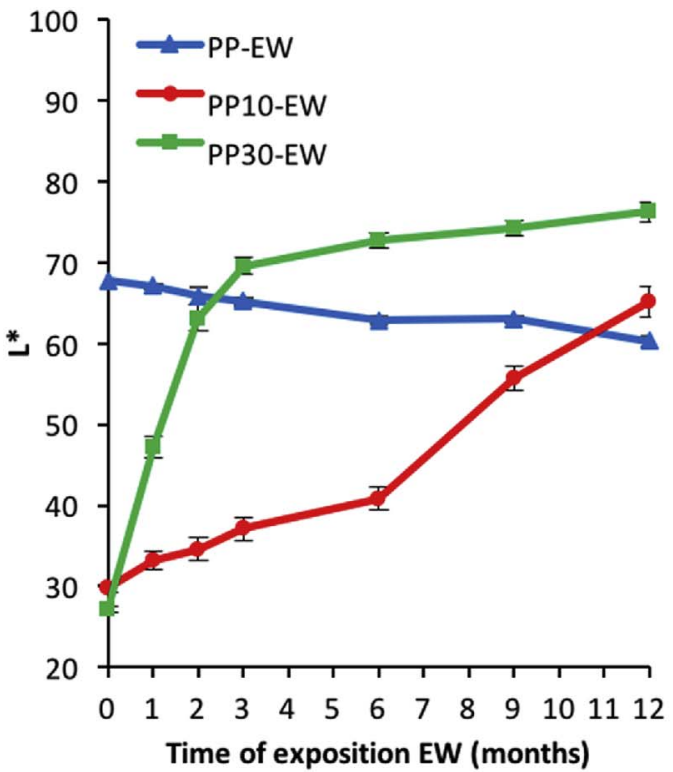

weathered PP10 presented higher a* coordinate value (about 3 ) than non-weathered PP and PP30 (both about 1). This can be attributed to a greater extractives (whose color is reddish) migration at the surface during moulding process for low fiber rate than for higher fiber content because of steric hindrance due to holocellulose and lignin [42] [43]. The higher extractives proportion at the surface of the lowest fiber rate biocomposite demonstrated by higher a* parameter value, was certainly due to extractives whereas steric hindrance due to holocellulose and lignin limits their migration at PP30 surface. Otherwise, the presence of vegetal fibers induced high chromatic variations of reinforced materials over the expositions. Indeed, a* value of biocomposites diminished whatever the type of weathering demonstrating a red color loss. This can be attributed to extractives and red chromophores degradation or removal due to radiation and rain for EW and spray for AW.

As regards b* coordinate changes, PP30 underwent yellowing during the first stage until 6 months (EW) and $500 \mathrm{~h}$ (AW), then $\mathrm{b}^{*}$ decreased. This evolution has already been observed by Peng et al. demonstrating that yellow paraquinones and photooxidative products formation due to presence of chromophore comprised of carbonyl groups was firstly favored. This preceded the further reduction of paraquinones part into hydroquinones. However, the quinones formation mechanism occurred slower during exterior ageing. Indeed, PP30AW rose from 1.91 for non-aged sample to 2.45 after $500 \mathrm{~h}$ then drastically dropped to 0.20 after $1000 \mathrm{~h}$ whereas PP30-EW increased to 3.11 then decreased to 2.32 after 12 months. Similarly, $b *$ value of PP10-AW decrease rate exceeded PP10-EW one. So, in our experimental conditions, chamber testing might be favourable for accelerating the degradation phenomenon.

\subsubsection{Gloss}

The light angular repartition profile of non-weathered and longestweathered materials ( $1000 \mathrm{~h}$ for AW and 1 year for EW) is shown in Fig. 8.

For non-weathered sample, maximum intensity of the specular peak dropped with the vegetal fibers rate meaning that brightness decreased. Some irregularities brought by the presence of short hemp fibers at the sample surface were responsible for less smooth surfaces.

After ageing, gloss was reduced for all materials. Indeed, the peak was no longer prominent after weathering and specular zones were no longer well defined, especially for PP30 for which peak almost

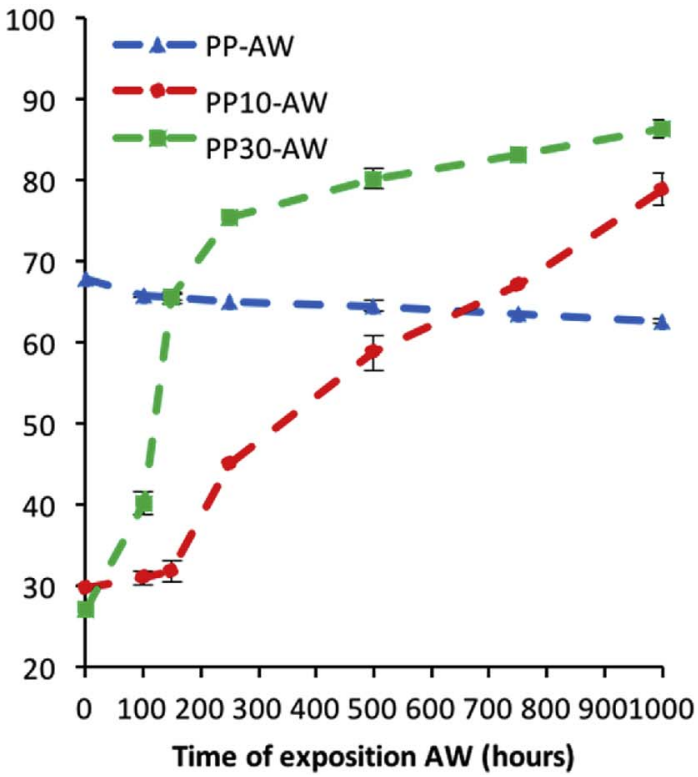

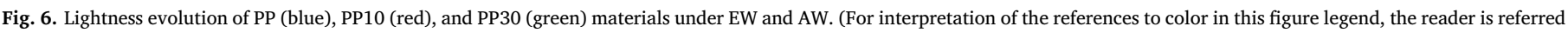
to the Web version of this article.) 


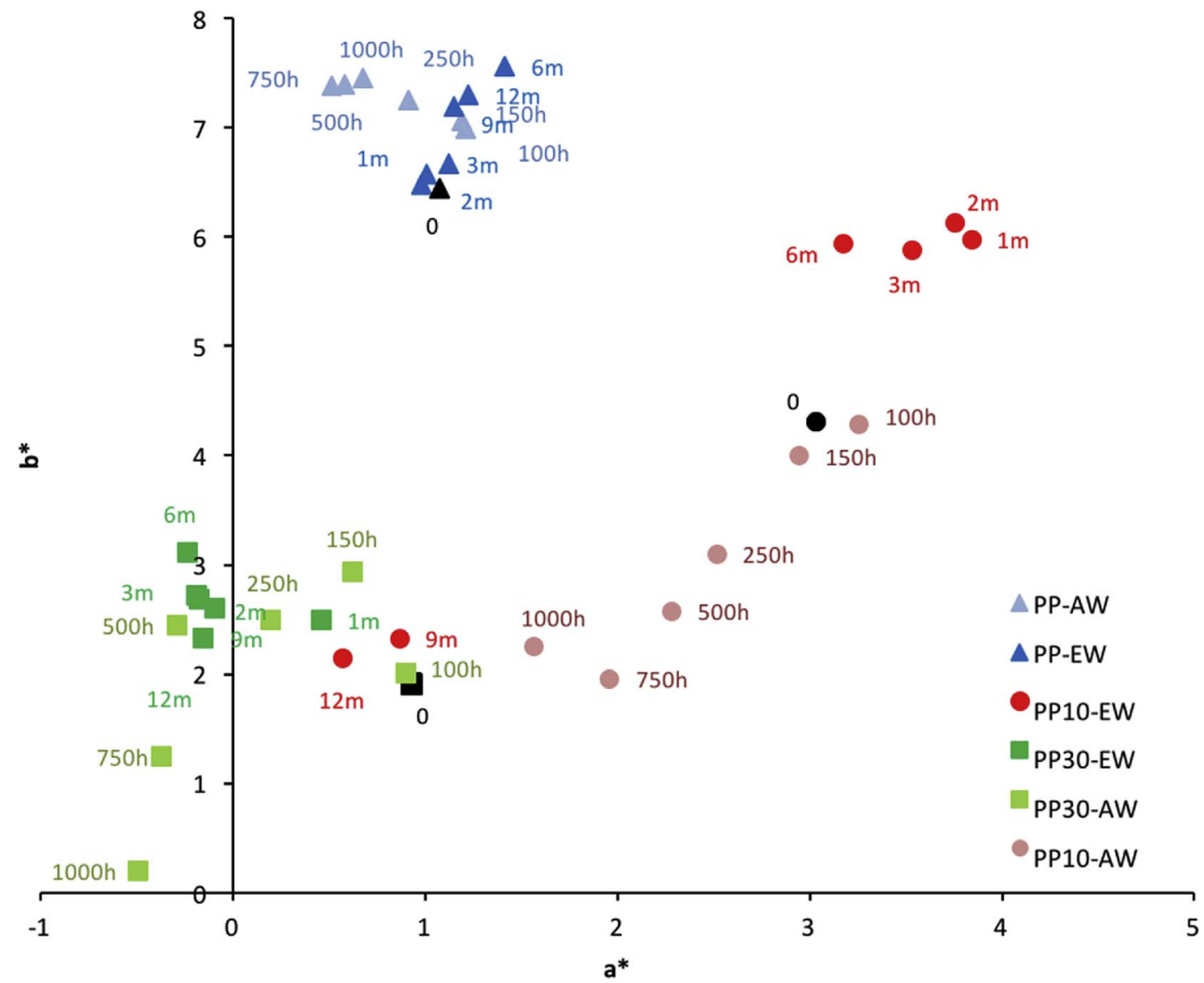

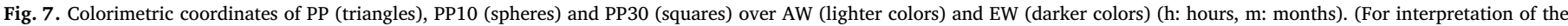
references to color in this figure legend, the reader is referred to the Web version of this article.)

disappeared due to diffuse reflection enhancement. No significant difference between PP30-AW and PP30-EW curves was observed. Nevertheless, aged neat PP exhibited short and broad symmetric peak that was extremely less intense than PP-UW one, signifying that polymer was particularly affected. Indeed, the maximum radiometric power value went from 17,094 u.a. to 2676 u.a. and 264 u.a. after EW and AW respectively. Thus, gloss and smoothness decreased faster in
$1000 \mathrm{~h}$ of artificial ageing than in one year of outdoor natural one. PP10 went through the same tendency.

Evolutions of gloss parameters throughout weathering are presented in Fig. 9.

$\mathrm{G}_{1}$ and $\mathrm{G}_{2}$ of PP-AW significantly decreased from 235 and 4275 to 1 and 5 respectively for the first $250 \mathrm{~h}$ whereas $\mathrm{G}_{1}$ and $\mathrm{G}_{2}$ of PP-EW took one year to go down to 34 and 12 respectively. PP10-AW reached

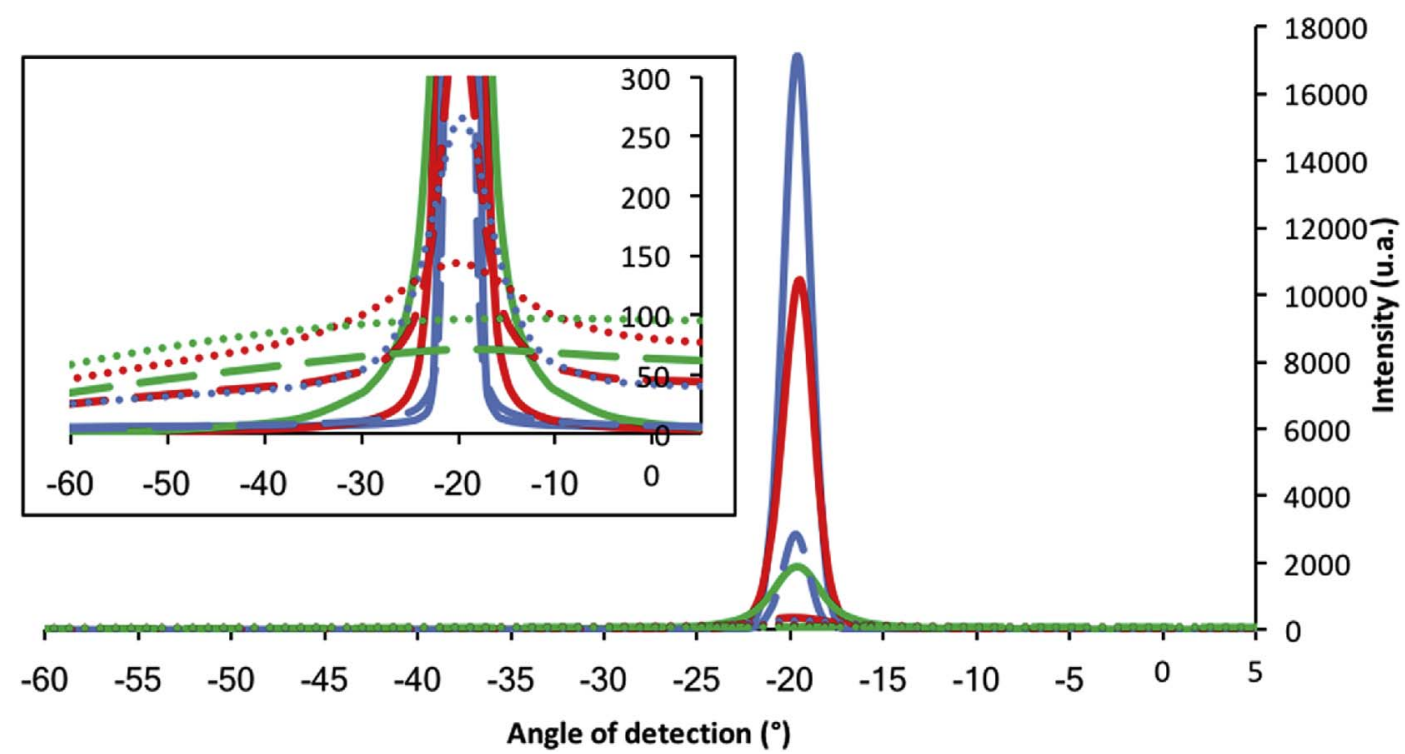

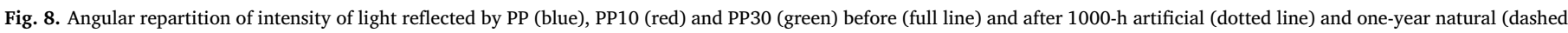
line) ageing. (For interpretation of the references to color in this figure legend, the reader is referred to the Web version of this article.) 

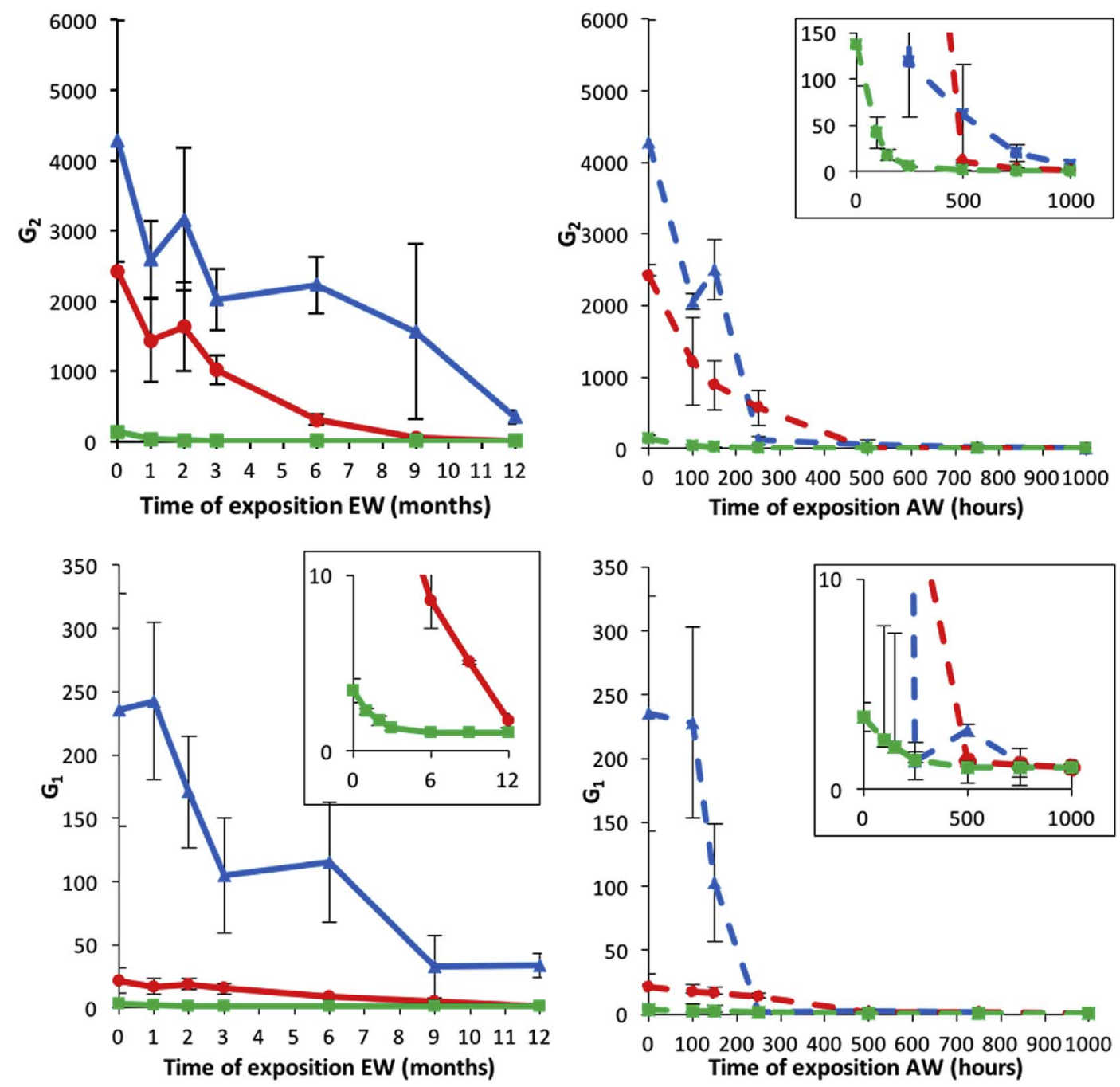

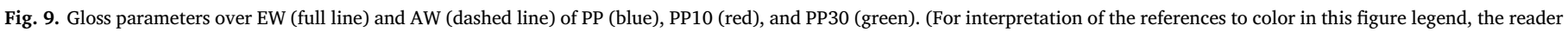
is referred to the Web version of this article.)

approximately 1 whatever the gloss ratio after longer time $(500 \mathrm{~h})$ whereas PP10-EW reached 9 (G1) and 1 (G2) value ratio after 9 and 12 months respectively. Both PP30-AW and PP30-EW parameters rapidly tended to 1 suggesting that intensity level reached a same level whatever the detection angle. As previously seen, PP was mostly degraded. As regards gloss variations, this trend was confirmed for artificial and outdoor ageing. Moreover, the ratio cannot drop below 1, so the comparison between PP30 and PP decrease rates cannot directly be compared since non-weathered PP30 already exhibited low gloss parameters close to 1 and thus swiftly reached the lowest parameter.

\subsection{Surface aspect}

\subsubsection{Roughness}

Average roughness was estimated by altitude variations measurement at the samples surface. Fig. 10 gathers non-aged and 1000-h artificially and one-year naturally aged materials. Before ageing, materials surface was relatively smooth. Some surface crackles progressively appeared afterwards, deepened and propagated gradually with ageing time. It is observed that the surface pictures differed according to the kind of weathering and the material and artificial weathering induced more surfaces deterioration. Finally, differences are noted according to the material as neat PP presented regular microcracks whose depth is higher after accelerated ageing. On the contrary, PP30 exhibited some dispersed hollows due to hemp fibers removal or protrusion caused by exterior parameters [8].
Fig. 11 clearly emphasizes the roughness continuous increase of all materials. By comparing EW and AW graphs, the highest degradation kinetic measured through average roughness parameter during exterior weathering was attributed to biocomposites whereas neat PP roughness outstripped during artificial weathering.

\subsection{Statistical analysis}

The previous observations do not corroborate the well-known higher sensitivity of biocomposites than conventional glass fibers composites face to UV radiation, temperature and humidity [1,44,45]. In view of properties changes, neat PP was globally particularly degraded due to artificial degradation. Therefore, parameters implemented in the laboratory chamber that strongly affected neat polymer stability may have been over-represented. PCA analysis will permit to understand and clarify these differences.

\subsubsection{Global degradation mechanisms}

All along the exposition, neat PP and biocomposites properties evolved at different rates. Moreover, depending on the property, the higher degradation kinetic was recorded either for PP or PP30 after artificial weathering whereas the contrary was noted after outdoor ageing. Thus, in order to verify the mechanisms and understand the observed differences, PCA is used to consider all studied properties.

The correlation circles allow representing the profile of correlations 


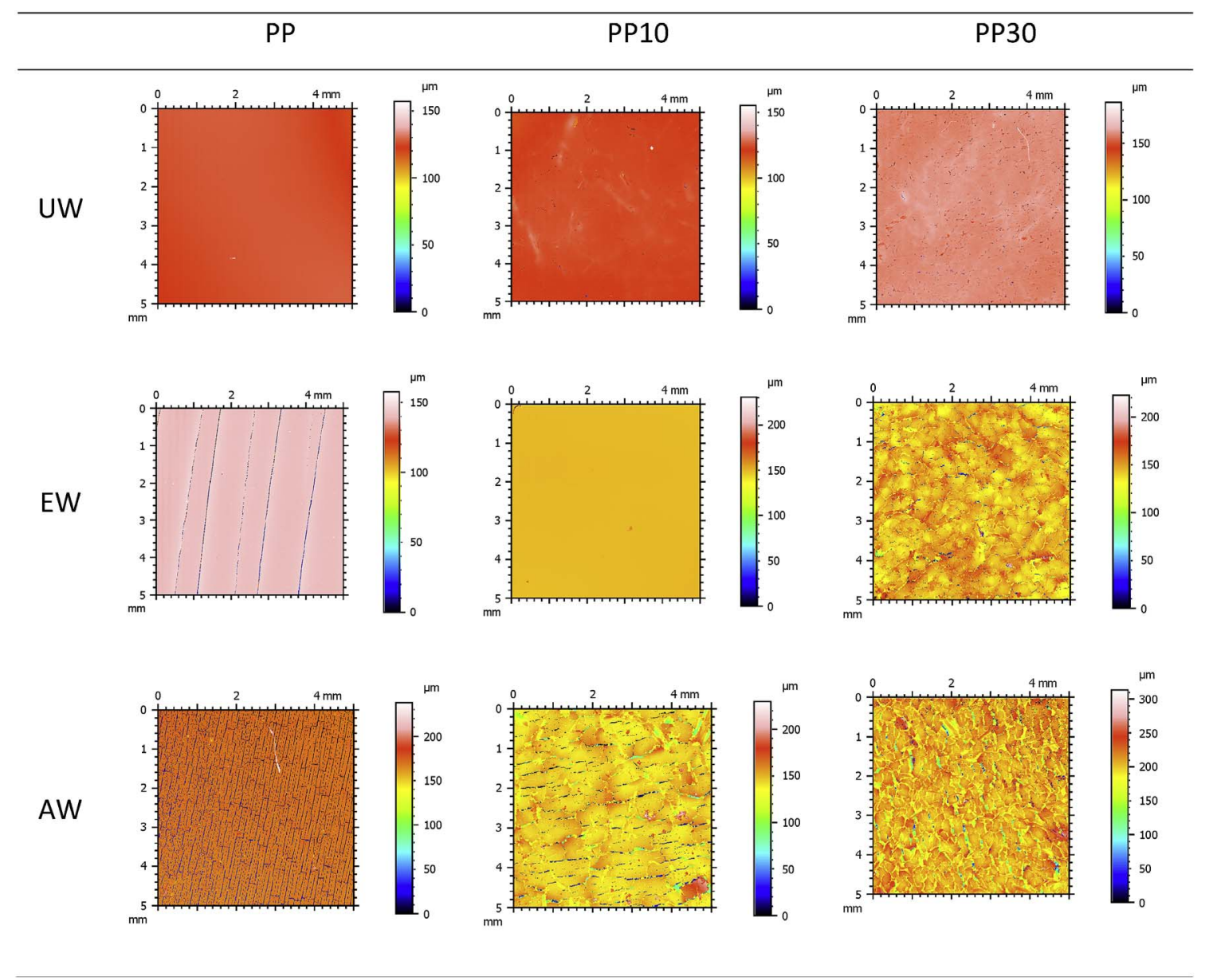

Fig. 10. Surface images of PP, PP10 and PP30 before (UW) and after artificial (AW) and exterior (EW) weathering.
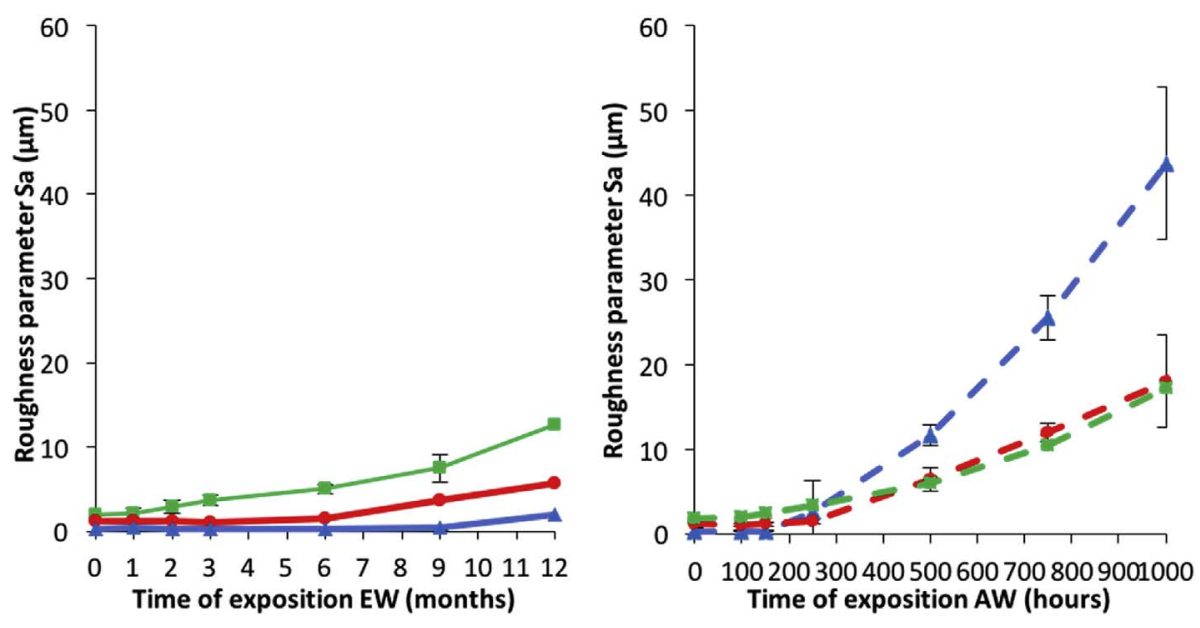

Fig. 11. Roughness parameter evolution of PP (blue), PP10 (red) and PP30 (green) over AW and EW. (For interpretation of the references to color in this figure legend, the reader is referred to the Web version of this article.)

between variables and can bring elements on causal relationships (Fig. 12). If the proximity between variables measured after EW differs from that measured after AW, we can assume that different mechanisms of degradation occurred. For this purpose, values were normalized to non-weathered state values in order to only consider the influence of time of weathering on properties changes for accurate interpretation of global degradation mechanisms induced by exposure. It can be noticed that positions of variables projected on the two circles globally do not differ. Gloss parameters, microstructure and mechanical properties are effectively well defined and positively correlated with the first principal component PC1 (horizontal axis). On the contrary, lightness is positively represented by PC2 for both ageing. Since weathering times are mainly organized according to PC1 and fiber loading according to PC2 (Fig. 13), normalized stiffness, conventional deflection stress and crystallinity ratio variables discriminate samples weathered at different ageing times. Finally, A1, A2 and A4 assigned to ketones and acids, to aldehydes and esters and to vinyls normalized absorption bands respectively equally contribute to PC1 and PC2. Otherwise, b* coordinate was far away from the two circles meaning that it was not well projected. Thus $\mathrm{b}^{*}$ colorimetric parameter cannot be interpreted.

Variables representing roughness parameter Sa and lactone maximum absorbance A3 contribute at different rates to PC1 and PC2 

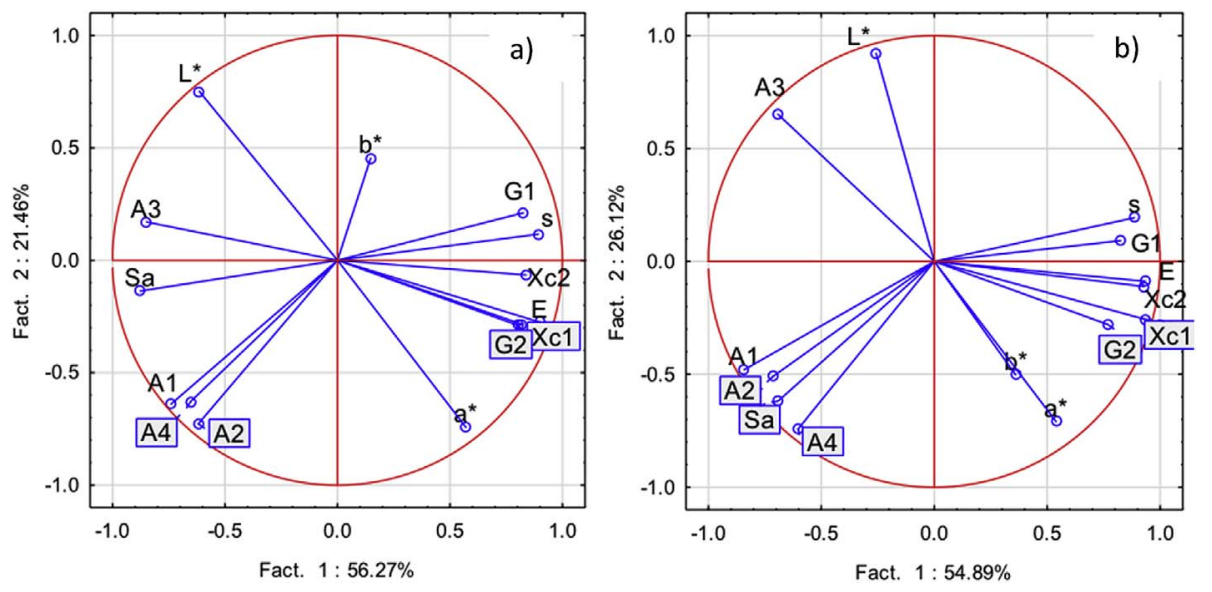

Fig. 12. Correlation circles of normalized variables under EW (a) and AW (b).
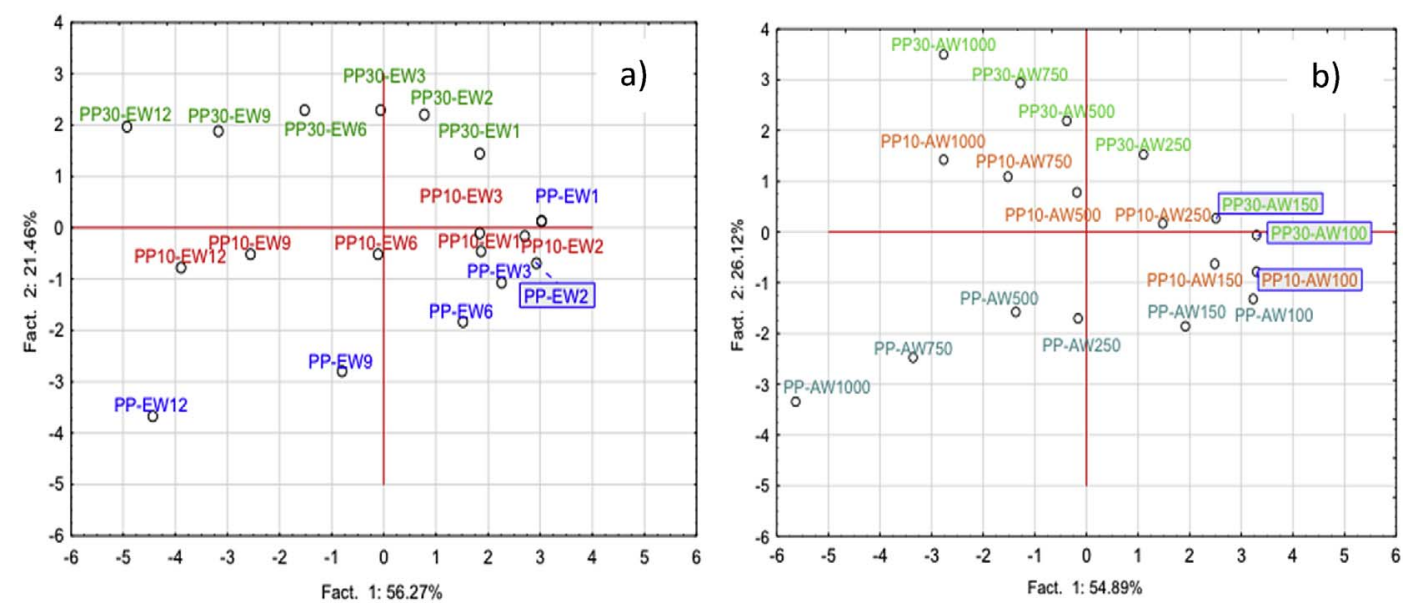

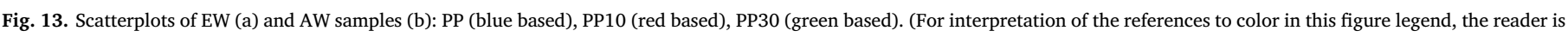
referred to the Web version of this article.)

principal components axes drawing. Indeed, A3 and Sa are close to PC1 carrying the highest rate of information of the cloud of data (almost $56 \%$ ) for EW. But these variables get more contribution to PC2 for AW. By simultaneous interpretation of subjects scatterplots and correlation circles, it is deduced that these parameters mostly discriminate the weathering time according to PC1 than fiber rate according to PC2 for EW (Figs. 12 and 13). On the contrary, for AW, Sa and A3 mainly distinguish fiber loadings through PC2. Indeed, strong differences of evolution trend of roughness and lactone maximum absorbance between PP, PP10 and PP30 were observed (Figs. 5 and 11). Short-term induction times of $150 \mathrm{~h}$ and $100 \mathrm{~h}$ respectively before the increase of parameters were verified for PP-AW whereas they increased after 6 months and 1 month respectively for PP-EW. This fact maybe induced the main discrimination of fiber loadings for AW (Fig. 13b). Thus, the difference of A3 and Sa positions between AW and EW is explained by the decomposition acceleration generated by the artificial ageing. Otherwise, they remain opposed according to PC1 axis whatever the kind of weathering.

Formation of cracks (Sa variations) were favored by UV rays and rain rather than high temperature [46]. Indeed, it was shown that temperature has not altered the crack growth mechanism [47]. Moreover, it has been deduced from infrared spectroscopy that hydrolysis could be responsible for carboxylic acid and ketone functional groups continuously fast increase for AW. Therefore, spray step representing rainfall might accelerate polymer chains scissions. Moreover, water might enhance the diffusion of oxygen in the matter favoring chains oxidation. So, spray and UV radiation steps especially inducing surface aspect changes could be over-represented. Also, in this case, lignin component found in vegetal fibers certainly acted as antioxidant after extended-time artificial exposure since the increase of the roughness and oxygenated products of artificially aged PP30 kinetic was lower $[5,48]$.

\subsubsection{Temporal equivalence}

The objective is to find eventual similar behaviour between naturally exteriorly (EW) and artificially (AW) weathered samples. Hence, to assess eventual temporal equivalence, individuals living in a multidimensional space whose dimensions number corresponds to the number of variables, were projected on a plan to easily perceive the proximities (Fig. 14). As previously, normalized variables were considered for only considering influence of exposition.

PP-AW100 and PP-EW3 present almost same coordinates according to PC1 axis to which all properties are mostly linked. Therefore, these materials are supposed to present same degradation rate according to the studied properties. Otherwise, they are also close to each other according to PC1 corresponding to the most important linear combination characterized by the most of variables and capturing the largest information (75\%). PP-AW250 and PP-EW12 present almost same coordinates according to PC1 and PC2. Thus, acceleration factors were calculated by the ratio between time of natural weathering and that of artificial weathering. They were estimated at 22 and 35 at these precise periods. Indeed, it is evident that non-linear evolution induces different acceleration factors according to the weathering stage. However, ketone and acid groups absorbance represented by A1 only verified the first equivalence whereas most of other properties mainly confirmed the second one. In literature, Lv et al. determined acceleration factor of 

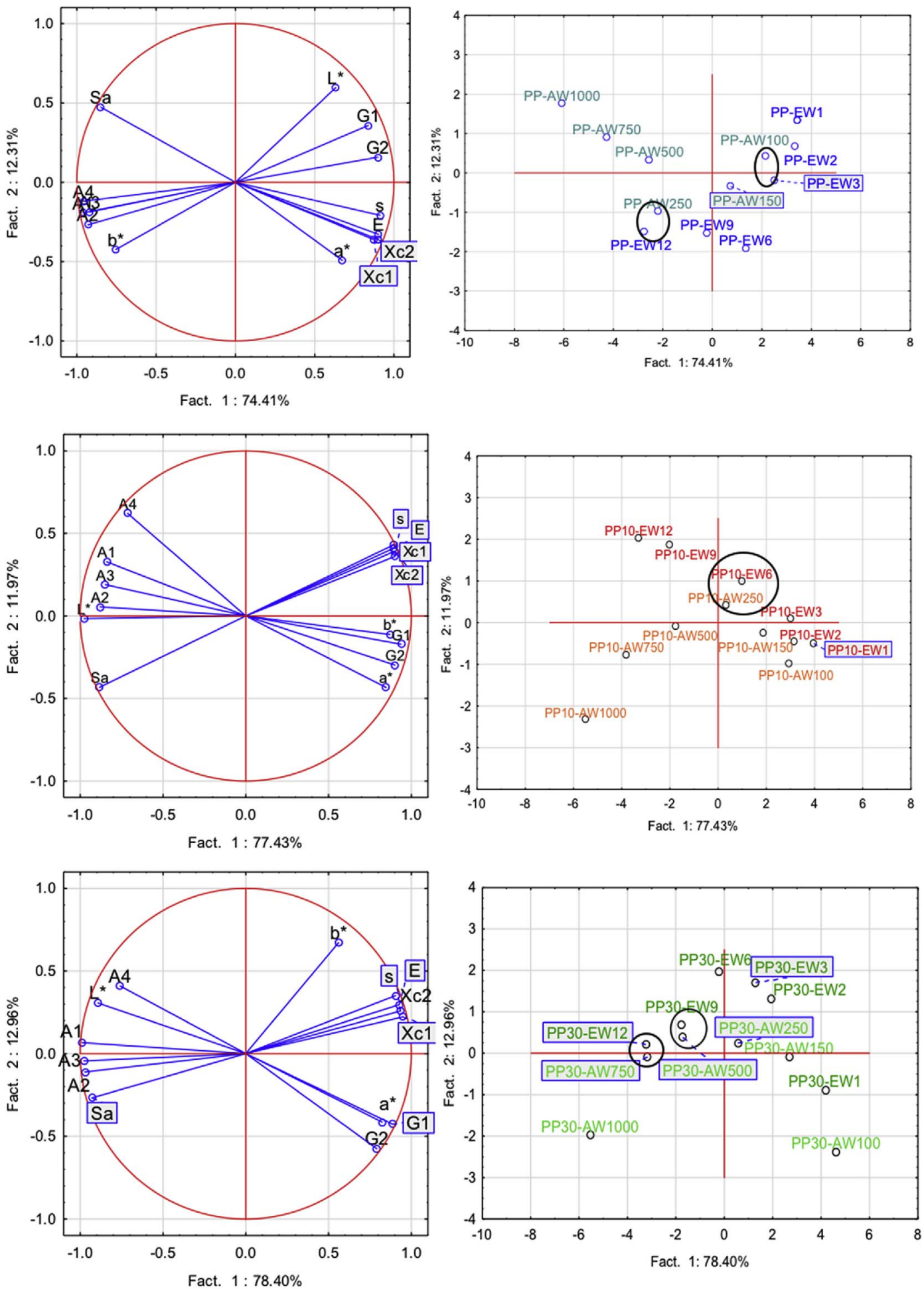

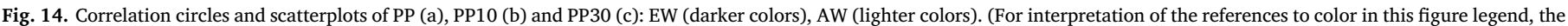
reader is referred to the Web version of this articile.)

PP only thanks to carbonyl index. The values scale ranged from 8.2 to 30 depending on the outdoor conditions and thus included the first value found in our study [25]. Similarly, the acceleration factors calculated from accelerated and natural ageing of a different polyolefin that was polyethylene, equaled 29 and 16 because they were determined from carbonyl absorbance and elongation at break evolution respectively [26]. So values were different according to the property.

As regards biocomposite loaded at $10 \mathrm{wt} \%$ of hemp fibers, PP10AW100 is related to PP10-EW2. Otherwise, $250 \mathrm{~h}$ and 6 months also generated same amounts of damage. Thus, the acceleration factors equal almost 14 and 17.5. In addition, by comparison with neat PP, PP10 required two times higher of natural exposure duration than PP to reflect $250 \mathrm{~h}$ of ageing in the QUV chamber.

Finally, as for previous materials, two temporal correspondences are given for PP30. Indeed, the two last natural weathering times 9 and 12 months coincide with 500 and $750 \mathrm{~h}$ respectively. So acceleration factors are 13 and 12. The two acceleration factors are almost equivalent. This can be justified by the fact that the two sampling were very close in 
time as much outside ( 9 and 12 months) as in the chamber $(500 \mathrm{~h}$ and $750 \mathrm{~h}$ ). Also, plots of properties such as carbonyl groups maximum absorbance, conventional deflection stress and elastic modulus as a function of weathering time present linear correlation coefficients superior to 0.90 . This can justify the low difference between acceleration factors since for linear evolution, the ratio between the slope of EW and AW corresponds to acceleration factor.

\section{Conclusion}

This work aimed to perform natural and artificial ageing of neat PP and biocomposites and correlate the two weathering conditions. Results showed that conditions of irradiation, humidity, temperature and water spraying chosen in this work accelerated oxidation kinetics and enhanced mechanical performance decrease under artificial weathering compared to outdoor conditions. The natural fibers photo-oxidation mechanisms inducing surface color variations of biocomposites were accentuated in the QUV chamber. $\mathrm{a}^{*}$ and $\mathrm{b} *$ colorimetric parameters decrease due to carbohydrates and lignin components decomposition was mostly intensified through artificial ageing. Smooth surface aspect of samples was also altered. Otherwise, the type of roughness differed according to the material with regular cracks for neat PP and some holes for the biocomposite with the highest fiber rate limiting the surface gloss.

Otherwise, results showed that modulus decrease of neat PP is more important than those of biocomposites after artificial ageing. Elsewhere it was observed that the degradation generally increased with the fiber rate after outdoor weathering whereas it decreased after artificial one. It also dug the cracks and holes formed after decomposition causing more deep cracks at neat PP surface.

PCA allowed comparing artificial and exterior weathering. It was found that correlation circles were quite similar apart from variables whose profile exhibited induction stage. Thus, this statistical method has disclosed a relationship between outside and chamber weathering. It permitted to conclude that artificial ageing more accelerated neat PP degradation maybe due to overrepresentation of factors in cycles than those found out of doors and sensitivity of PP face to short cyclical changes.

Depending on the material, different acceleration factors were estimated from PCA. Indeed, one-year natural exposure of neat polymer was represented by $250 \mathrm{~h}$ of accelerated ageing whereas $750 \mathrm{~h}$ were required for the highest fiber loading composite. Contrary to studies found in literature that classically put face together values of a same property obtained after accelerated and natural ageing, this statistical method used to estimate acceleration factors allowed to take into account all parameters at the same time. It could be interesting to generalize this approach to other materials and other quantitative parameters representative of weathering.

\section{Acknowledgements}

This research did not receive any specific grant from funding agencies in the public, commercial, or not-for-profit sectors.

\section{Appendix A. Supplementary data}

Supplementary data related to this article can be found at http://dx. doi.org/10.1016/j.polymdegradstab.2018.01.002.

\section{References}

[1] A. Shahzad, Hemp fiber and its composites - a review, J. Compos. Mater. 46 (2012) 973-986, http://dx.doi.org/10.1177/0021998311413623.

[2] M.Z. Ahmad Thirmizir, Z.A. Mohd Ishak, R. Mat Taib, S. Rahim, S. Mohamad Jani, Natural Weathering of kenaf bast fibre-filled poly(butylene succinate) composites: effect of fibre loading and compatibiliser addition, J. Polym. Environ. 19 (2010) 263-273, http://dx.doi.org/10.1007/s10924-010-0272-2.

[3] C. Homkhiew, T. Ratanawilai, W. Thongruang, Effects of natural weathering on the properties of recycled polypropylene composites reinforced with rubberwood flour, Ind. Crop. Prod. 56 (2014) 52-59, http://dx.doi.org/10.1016/j.indcrop.2014.02. 034.

[4] S. Butylina, M. Hyvärinen, T. Kärki, A study of surface changes of wood-polypropylene composites as the result of exterior weathering, Polym. Degrad. Stabil. 97 (2012) 337-345, http://dx.doi.org/10.1016/j.polymdegradstab.2011.12.014.

[5] I. Spiridon, K. Leluk, A.M. Resmerita, R.N. Darie, Evaluation of PLA-lignin bioplastics properties before and after accelerated weathering, Compos. B Eng. 69 (2015) 342-349, http://dx.doi.org/10.1016/j.compositesb.2014.10.006.

[6] K.C.C.C. Benini, H.J.C. Voorwald, M.O.H. Cioffi, Mechanical properties of HIPS/ sugarcane bagasse fiber composites after accelerated weathering, Process Eng. 10 (2011) 3246-3251, http://dx.doi.org/10.1016/j.proeng.2011.04.536.

[7] N.M. Stark, L.M. Matuana, Ultraviolet weathering of photostabilized wood-flourfilled high-density polyethylene composites, J. Appl. Polym. Sci. 90 (2003) 2609-2617, http://dx.doi.org/10.1002/app.12886.

[8] L. Soccalingame, D. Perrin, J.-C. Bénézet, S. Mani, F. Coiffier, E. Richaud, A. Bergeret, Reprocessing of artificial UV-weathered wood flour reinforced polypropylene composites, Polym. Degrad. Stabil. 120 (2015) 313-327, http://dx.doi. org/10.1016/j.polymdegradstab.2015.07.013.

[9] A. François-Heude, E. Richaud, E. Desnoux, X. Colin, Influence of temperature, UVlight wavelength and intensity on polypropylene photothermal oxidation, Polym. Degrad. Stabil. 100 (2014) 10-20, http://dx.doi.org/10.1016/j.polymdegradstab. 2013.12.038.

[10] J.W. Martin, R.A. Ryntz, J. Chin, R.A. Dickie, R.A. Ryntz, J. Chin, R.A. Dickie (Eds.), Service Life Prediction of Polymeric Materials: Global Perspectives, Springer Science \& Business Media, 2008, p. 537, , http://dx.doi.org/10.1007/978-0-38784876-1.

[11] X. Yang, X. Jiang, J. Hu, F. Wang, C. Hu, Relationship between physical and mechanical properties of accelerated weathering and outdoor weathering of PVCcoated membrane material under tensile stress, J. Ind. Textil. (2016), http://dx.doi. org $/ 10.1177 / 1528083716639062$.

[12] X. Yang, X. Ding, Prediction of outdoor weathering performance of polypropylene filaments by accelerated weathering tests, Geotext. Geomembranes 24 (2006) 103-109, http://dx.doi.org/10.1016/j.geotexmem.2005.11.002.

[13] Y. Azuma, H. Takeda, S. Watanabe, H. Nakatani, Outdoor and accelerated weathering tests for polypropylene and polypropylene/talc composites: a comparative study of their weathering behavior, Polym. Degrad. Stabil. 94 (2009) 2267-2274, http://dx.doi.org/10.1016/j.polymdegradstab.2009.08.008.

[14] X. Yang, X. Jiang, J. Hu, F. Wang, C. Hu, Relationship between physical and mechanical properties of accelerated weathering and outdoor weathering of PVCcoated membrane material under tensile stress, J. Ind. Textil. (2016), http://dx.doi. org/10.1177/1528083716639062.

[15] J.L. Philippart, C. Sinturel, R. Arnaud, J.L. Gardette, Influence of the exposure parameters on the mechanism of photooxidation of polypropylene, Polym. Degrad. Stabil. 64 (1999) 213-225, http://dx.doi.org/10.1016/S0141-3910(98)00191-8.

[16] M.D.H. Beg, K.L. Pickering, Accelerated weathering of unbleached and bleached Kraft wood fibre reinforced polypropylene composites, Polym. Degrad. Stabil. 93 (2008) 1939-1946, http://dx.doi.org/10.1016/j.polymdegradstab.2008.06.012.

[17] D.R. Bauer, Interpreting weathering acceleration factors for automotive coatings using exposure models, Polym. Degrad. Stabil. 69 (2000) 307-316, http://dx.doi. org/10.1016/S0141-3910(00)00074-4.

[18] G.R. Fedor, P.J. Brennan, Technical Bulletin (Q-LAB): Comparison between Natural Weathering and Fluorescent UV Exposures: UVA-340 Lamp Tests Results, (2011).

[19] J.S. Fabiyi, A.G. McDonald, Degradation of polypropylene in naturally and artificially weathered plastic matrix composites, Maderas Cienc. Tecnol. 16 (2014), http://dx.doi.org/10.4067/S0718-221X2014005000021 0-0.

[20] C. Badji, L. Soccalingame, H. Garay, A. Bergeret, J.-C. Bénézet, Influence of weathering on visual and surface aspect of wood plastic composites: correlation approach with mechanical properties and microstructure, Polym. Degrad. Stabil. 137 (2017) 162-172, http://dx.doi.org/10.1016/j.polymdegradstab.2017.01.010.

[21] L. Belec, T.H. Nguyen, D.L. Nguyen, J.F. Chailan, Comparative effects of humid tropical weathering and artificial ageing on a model composite properties from nano- to macro-scale, Compos. Part A Appl. Sci. Manuf 68 (2015) 235-241, http:// dx.doi.org/10.1016/j.compositesa.2014.09.028.

[22] J.B. Howard, H.M. Gilroy, Natural and artificial weathering of polyethylene plastics, Polym. Eng. Sci. 9 (1969) 286-294, http://dx.doi.org/10.1002/pen. 760090409.

[23] A. Jankowska, P. Kozakiewicz, Comparison of Outdoor and Artificial weathering using compressive properties, Wood Res. 59 (2014) 245-252.

[24] M. Crewdson, Outdoor weathering must verify accelerated testing, Antec 2011 (91) (2010) 260-266.

[25] Y. Lv, Y. Huang, J. Yang, M. Kong, H. Yang, J. Zhao, G. Li, Outdoor and accelerated laboratory weathering of polypropylene: a comparison and correlation study, Polym. Degrad. Stabil. 112 (2015) 145-159, http://dx.doi.org/10.1016/j. polymdegradstab.2014.12.023.

[26] A. Tidjani, R. Arnaud, A. Dasilva, Natural and accelerated photoaging of linear lowdensity polyethylene: changes of the elongation at break, J. Appl. Polym. Sci. 47 (1993) 211-216, http://dx.doi.org/10.1002/app.1993.070470203.

[27] Z.N. Azwa, B.F. Yousif, A.C. Manalo, W. Karunasena, A review on the degradability of polymeric composites based on natural fibres, Mater. Des. 47 (2013) 424-442, http://dx.doi.org/10.1016/j.matdes.2012.11.025. 
[28] C.A. Taylor, A. Amiri, D.C. Webster, C.A. Ulven, Long-term behavior of bio-composites for structural applications, CAMX 2016-Compos, Adv. Mater. Expo (2016), http://dx.doi.org/10.13140/RG.2.2.33964.87682.

[29] K.G. Martin, R.I. Tilley, CSIRO Australia, Division of Building Research Report 04-26, (1970).

[30] J.S. Han, J.S. Rowell, Chemical composition of fibers, in: R.M. Rowell, R.A. Young, J.K. Rowell (Eds.), Pap. Compos. From Agro-based Resour, CRC/Lewis Publishers, 1996, pp. 84-134.

[31] J. Acera Fernández, N. Le Moigne, A.S. Caro-Bretelle, R. El Hage, A. Le Duc, M. Lozachmeur, P. Bono, A. Bergeret, Role of flax cell wall components on the microstructure and transverse mechanical behaviour of flax fabrics reinforced epoxy biocomposites, Ind. Crop. Prod. 85 (2016) 93-108, http://dx.doi.org/10. 1016/j.indcrop.2016.02.047.

[32] ISO 877-1: Plastics - Methods of Exposure to Solar Radiation - Part 1: General Guidance, (2011).

[33] Pau-Uzein meteorological station, Real-time Weather Reports, (2016) http://www. infoclimat.fr/observations-meteo/temps-reel/pau-uzein/07610.html , Accessed date: 16 June 2017.

[34] EN ISO 4892-3: Plastics - Methods of Exposure to Laboratory Light Sources - Part 3: Fluorescent Lamps, (2013), pp. 2-14.

[35] ISO 178:2010, Plastics - Determination of Flexural Properties, (2010).

[36] ISO 2813: Coatings: Determination of Gloss Value at $20^{\circ}, 60^{\circ}$ and $85^{\circ},(2014)$, pp. $1-31$.

[37] L.H. Sperling, Introduction to Physical Polymer Science, fourth ed., John Wiley \& Sons, 2006, , http://dx.doi.org/10.1002/0471757128.ch9.

[38] N.M. Stark, L.M. Matuana, Influence of photostabilizers on wood flour-HDPE composites exposed to xenon-arc radiation with and without water spray, Polym. Degrad. Stabil. 91 (2006) 3048-3056, http://dx.doi.org/10.1016/j. polymdegradstab.2006.08.003.

[39] J.F. Rabek, Photostabilization of Polymers: Principles and Applications, Elsevier Applied Science, 1990, http://dx.doi.org/10.1007/978-94-009-07-47-8.
[40] S. Morlat, B. Mailhot, D. Gonzalez, J.L. Gardette, Photo-oxidation of polypropylene/ montmorillonite nanocomposites. 1. Influence of nanoclay and compatibilizing agent, Chem. Mater. 16 (2004) 377-383, http://dx.doi.org/10.1021/cm031079k.

[41] S.A. Jabarin, E.A. Lofgren, Photooxidative effects on properties and structure of high-density polyethylene, J. Appl. Polym. Sci. 53 (1994) 411-423, http://dx.doi org/10.1002/app.1994.070530404.

[42] D. Rosu, R. Bodîrləu, C.A. Teacə, L. Rosu, C.D. Varganici, Epoxy and succinic anhydride functionalized soybean oil for wood protection against UV light action, J. Clean. Prod. 112 (2016) 1175-1183, http://dx.doi.org/10.1016/j.jclepro.2015.07. 092.

[43] A.J. Vinha, A.G. Carvalho, M. Teixeira de Souza, C. Marangon Jardim, A. de Cassia Oliveira Carneiro, J. Luiz Colodette, Effect of extractives on wood color of heat treated Pinus radiata and Eucalyptus pellita, Maderas Cienc. Tecnol. 17 (2015) 857-864, http://dx.doi.org/10.4067/S0718-221X2015005000074.

[44] G. Dorez, L. Ferry, R. Sonnier, A. Taguet, J.-M. Lopez-Cuesta, Effect of cellulose, hemicellulose and lignin contents on pyrolysis and combustion of natural fibers, $\mathrm{J}$. Anal. Appl. Pyrol. 107 (2014) 323-331, http://dx.doi.org/10.1016/j.jaap.2014.03. 017.

[45] P. Wambua, J. Ivens, I. Verpoest, Natural fibres: can they replace glass in fibre reinforced plastics? Compos. Sci. Technol. 63 (2003) 1259-1264, http://dx.doi. org/10.1016/S0266-3538(03)00096-4.

[46] H. Du, W. Wang, Q. Wang, S. Sui, Y. Song, Effects of ultraviolet absorbers on the ultraviolet degradation of rice-hull/high-density polyethylene composites, J. Appl Polym. Sci. 126 (2012) 906-915, http://dx.doi.org/10.1002/app.36558.

[47] M.M. Thwe, K. Liao, Durability of bamboo-glass fiber reinforced polymer matrix hybrid composites, Compos. Sci. Technol. 63 (2003) 375-387, http://dx.doi.org/ 10.1016/S0266-3538(02)00225-7.

[48] Y. Peng, R. Liu, J. Cao, Y. Chen, Effects of UV weathering on surface properties of polypropylene composites reinforced with wood flour, lignin, and cellulose, Appl. Surf. Sci. 317 (2014) 385-392, http://dx.doi.org/10.1016/j.apsusc.2014.08.140. 